\title{
N-Heterocyclic Carbene/Lewis Acid Catalyzed Enantioselective Aerobic Annulation of $\alpha, \beta$-Unsaturated Aldehydes with \\ 1,3-dicarbonyl compounds
}

Danbo Xie, Dan Shen, Qiliang Chen, Jiaqi Zhou, Xiaofei Zeng,* and Guofu Zhong* College of Material, Chemistry and Chemical Engineering, Hangzhou Normal University

Hangzhou 310036 (China)

Email: chemzxf@hznu.edu.cn, zgf@,hznu.edu.cn

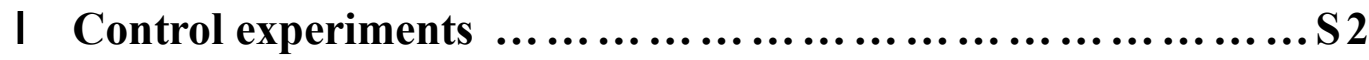

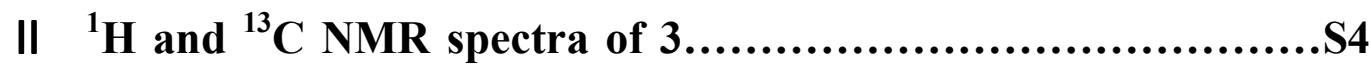

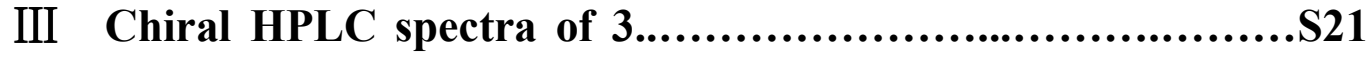




\section{Control experiments:}

1)<smiles>O=C/C=C/c1ccccc1</smiles>

$1 a$

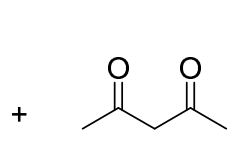

$2 \mathbf{a}$
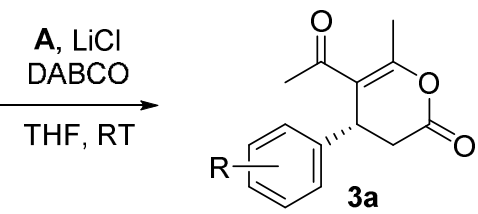

1) $\mathrm{N}_{2}$, no reaction

2) $\mathrm{O}_{2}, 4 \mathrm{~h}$, yield: $77 \%, 58 \%$ ee

2)

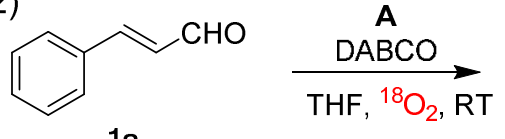<smiles>O=C(O)C=Cc1ccccc1</smiles>

3)

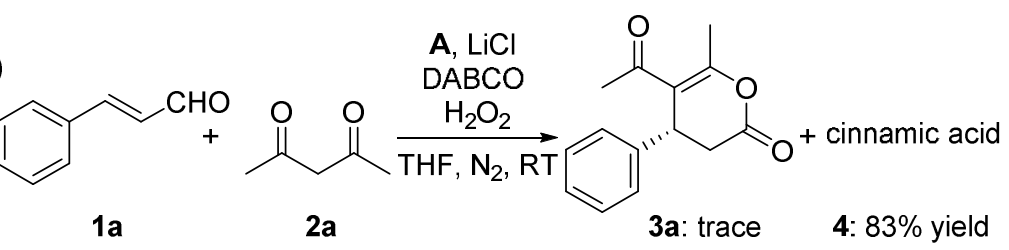

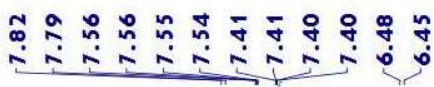
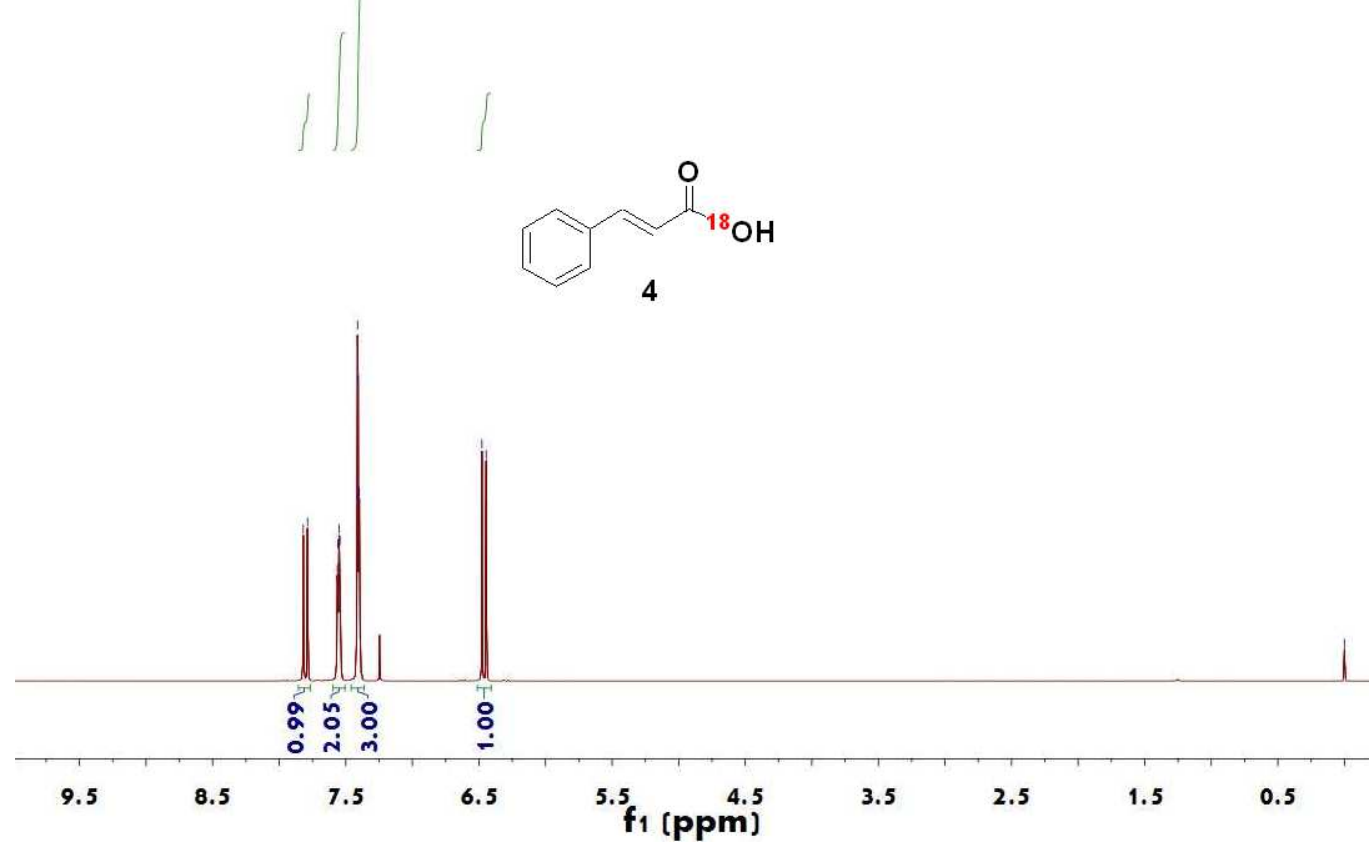


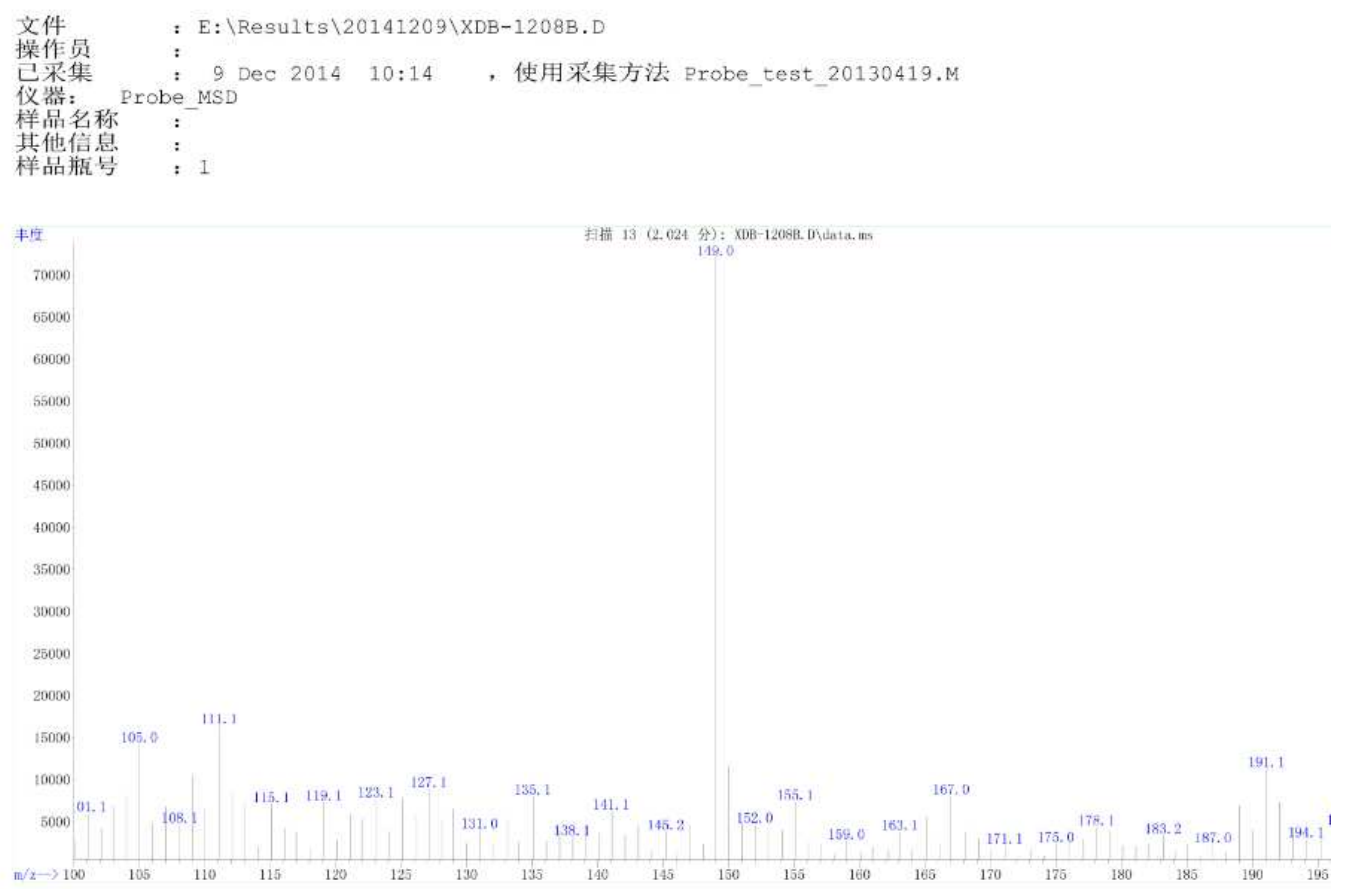


II. ${ }^{1} \mathrm{H}$ and ${ }^{13} \mathrm{C}$ NMR spectraof 3 .

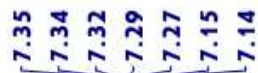

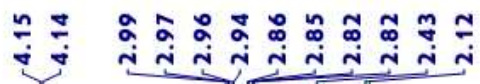

11
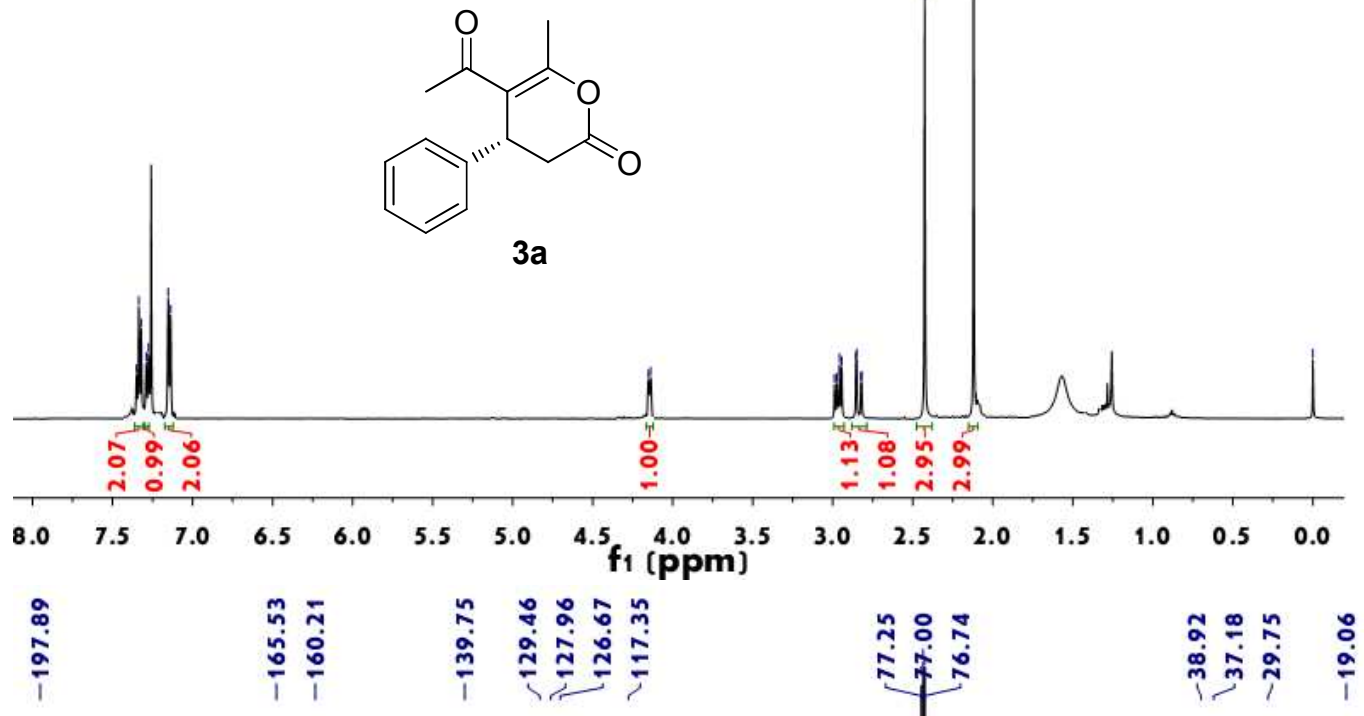<smiles>CC(=O)C1=C(C)OC(=O)C[C@H]1c1ccccc1</smiles>

$3 a$
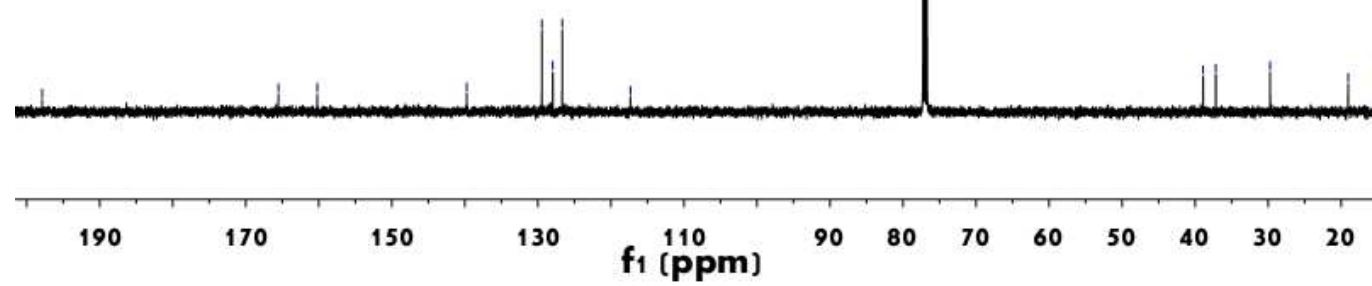


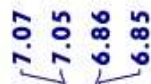

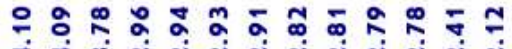

$\iint$
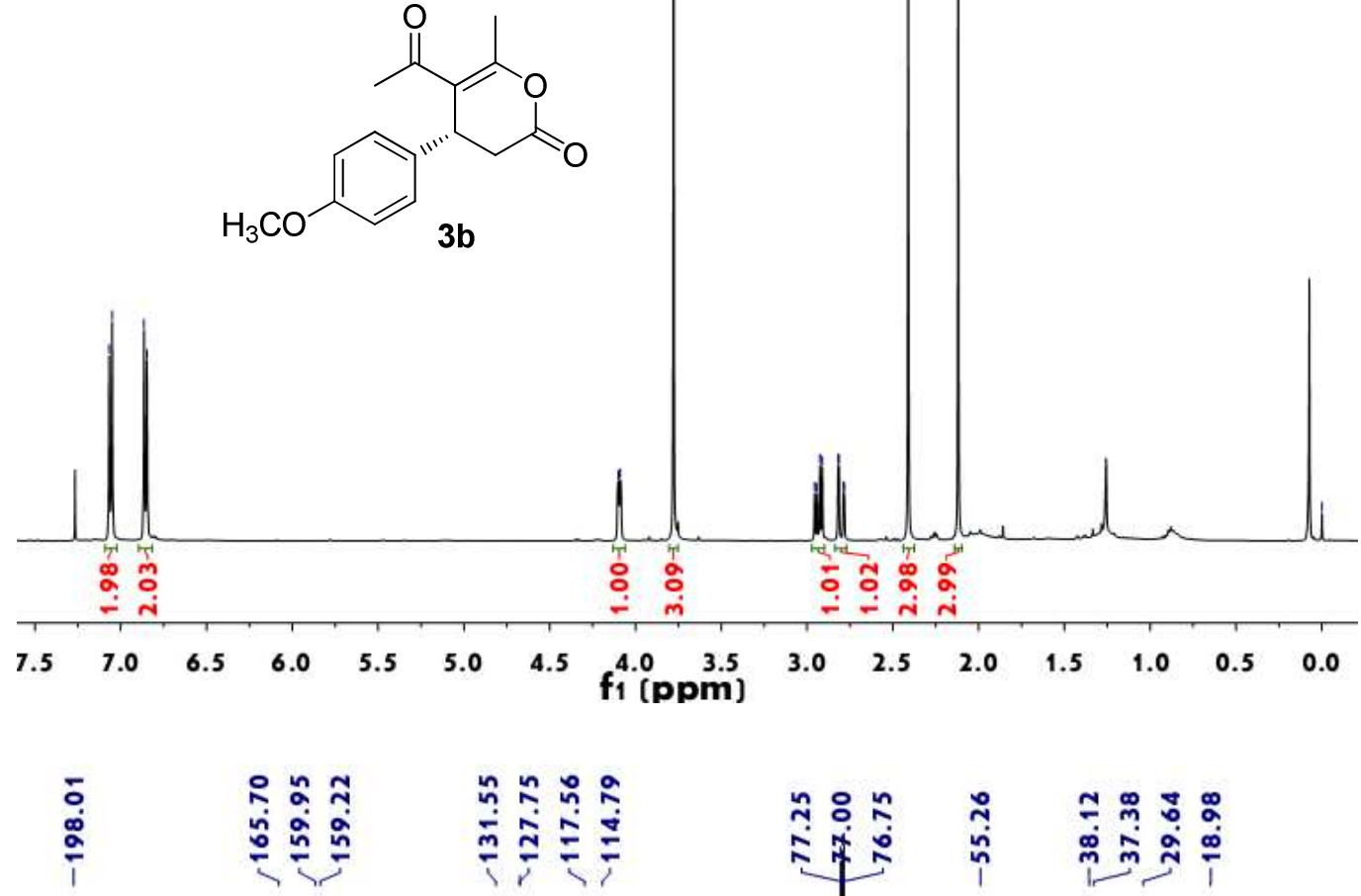

告苓<smiles>COc1ccc([C@H]2CC(=O)OC(C)=C2C(C)=O)cc1</smiles>
$3 b$
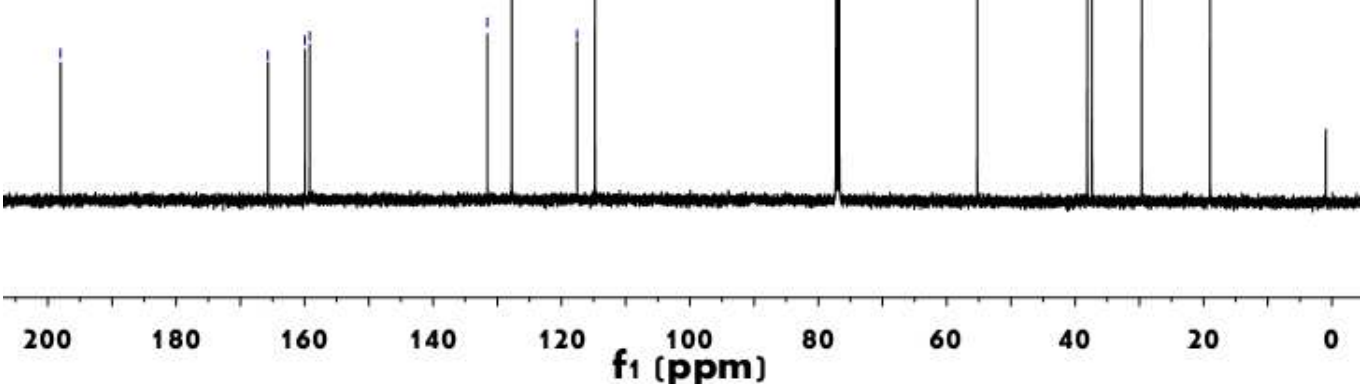

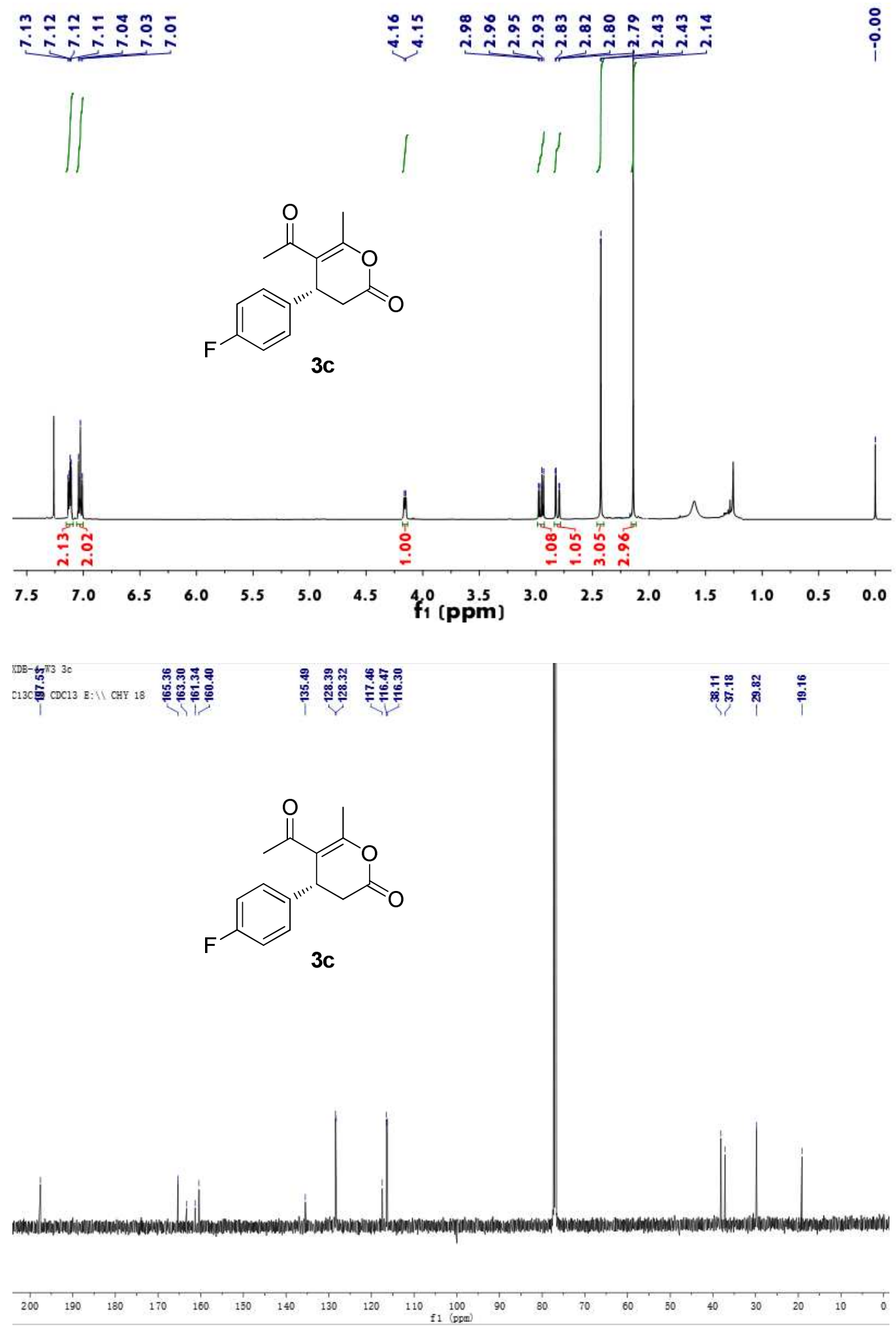

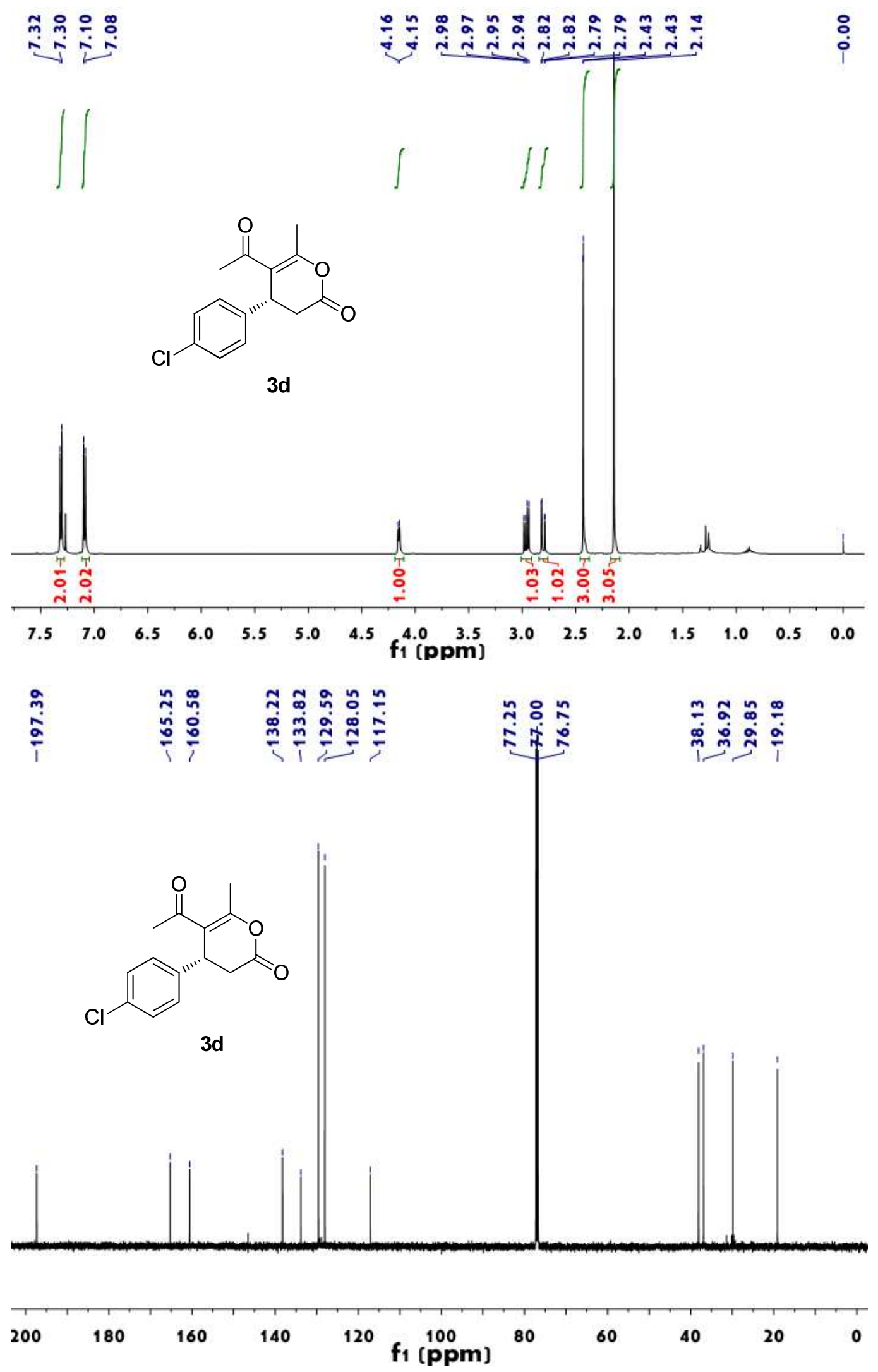

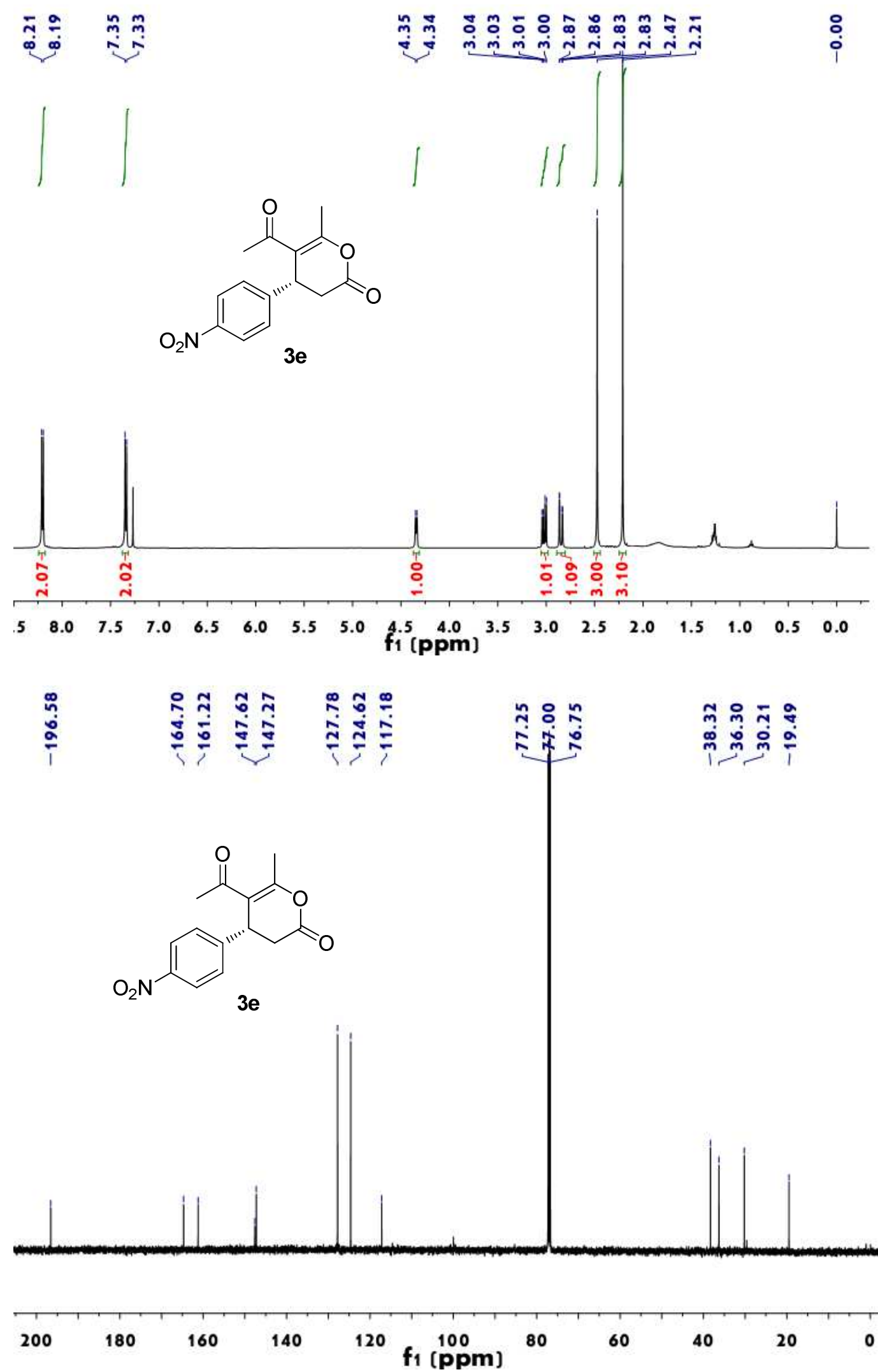

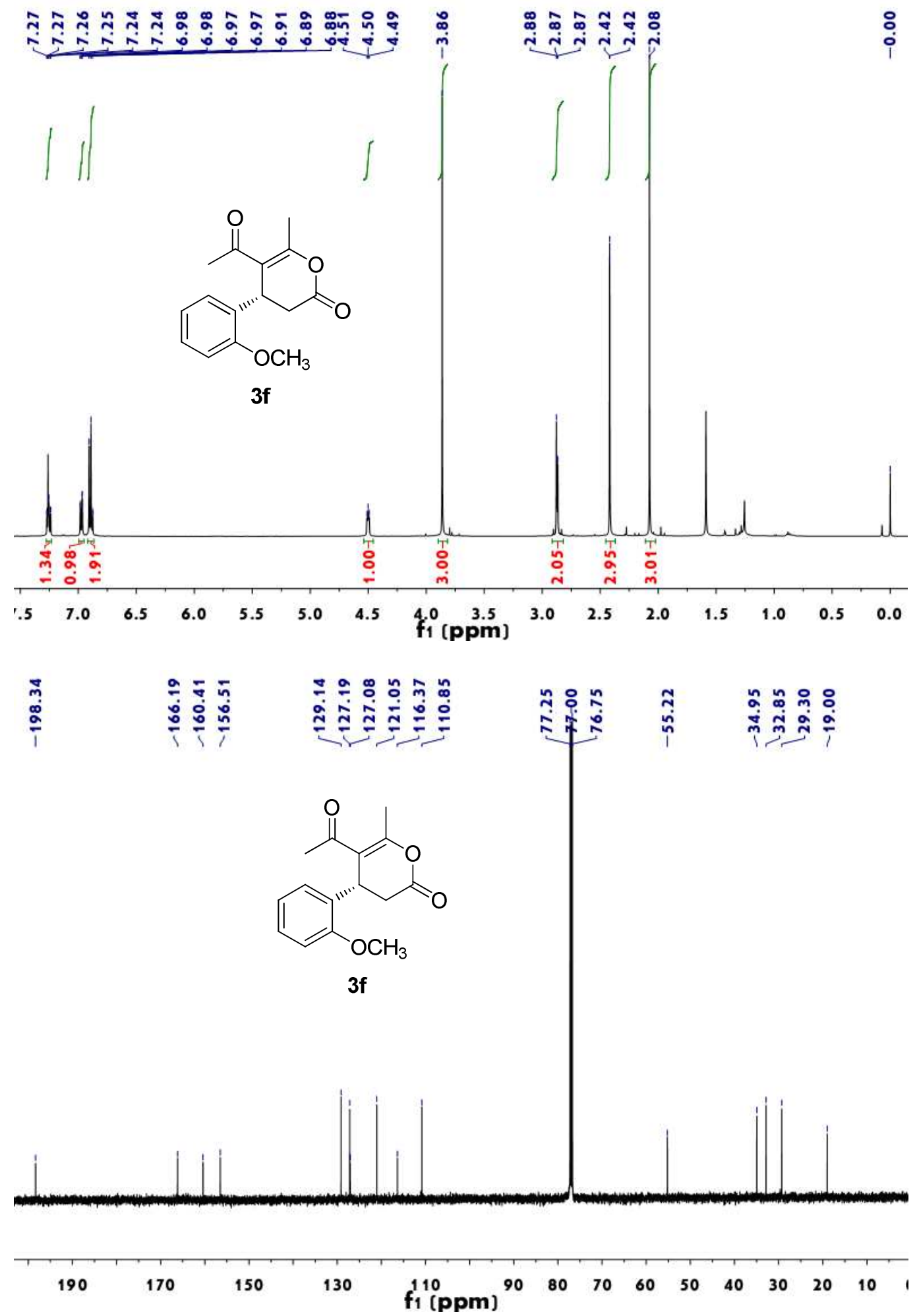

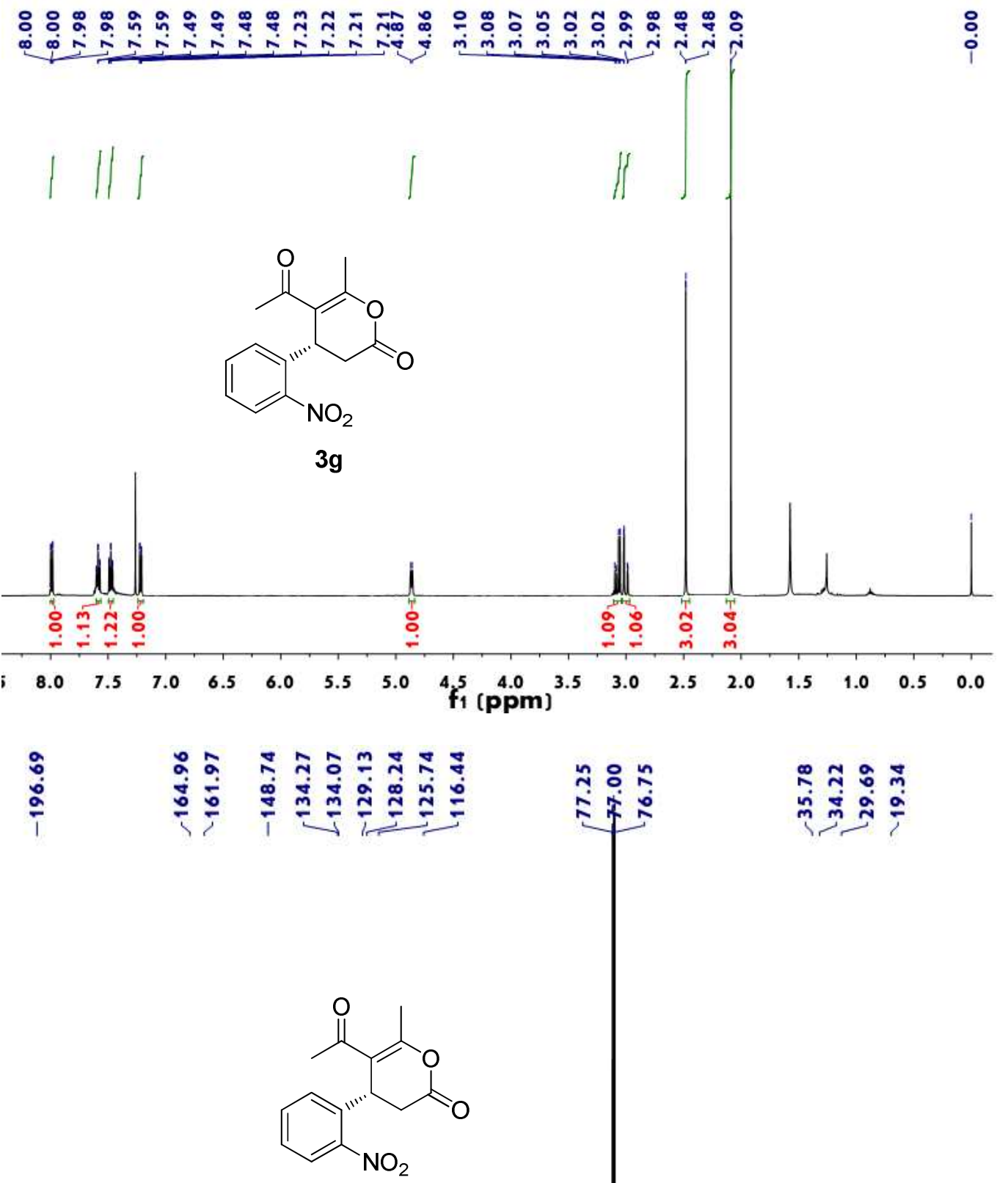

$3 \mathrm{~g}$
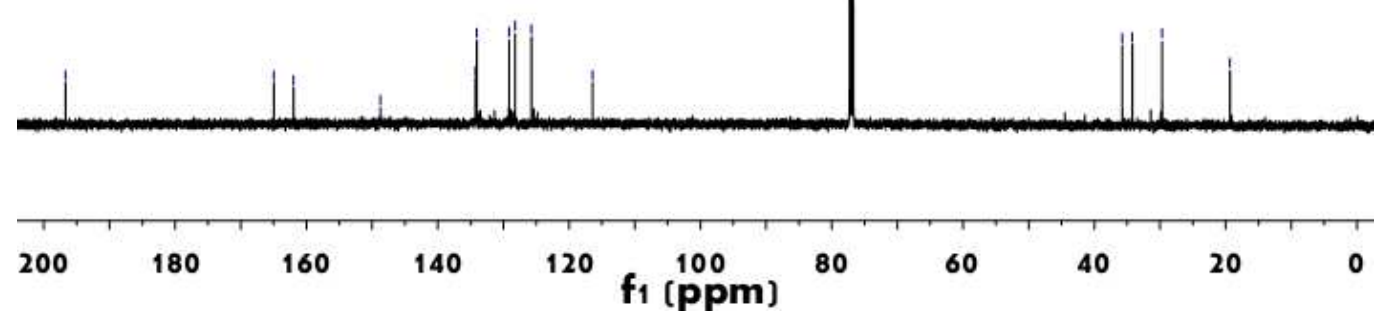
崩

華

$\stackrel{\circ}{i}$<smiles>CC(=O)C1=C(C)OC(=O)C[C@H]1c1ccco1</smiles>

$3 \mathrm{~h}$
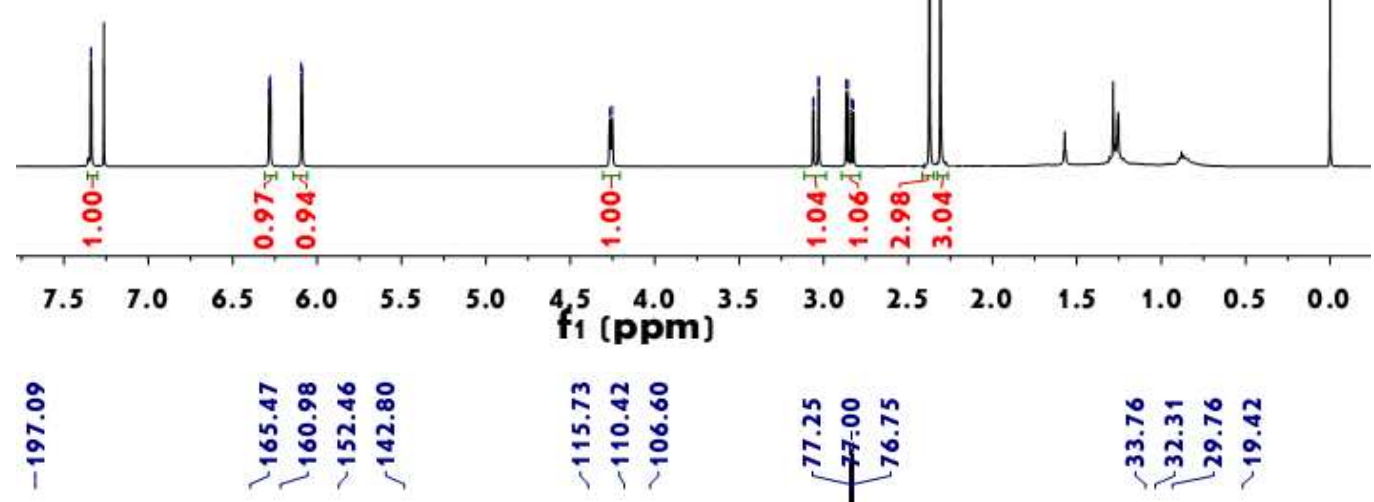

先究会

ำ- ำ

लै<smiles>CC(=O)C1=C(C)OC(=O)C[C@H]1c1ccco1</smiles>

$3 \mathrm{~h}$

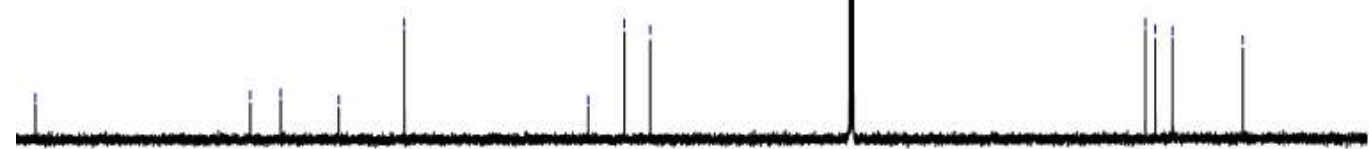

$\begin{array}{llllllllllllll}190 & 170 & 150 & 130 & 1,10 & 90 & 80 & 70 & 60 & 50 & 40 & 30 & 20 & 10\end{array}$ 


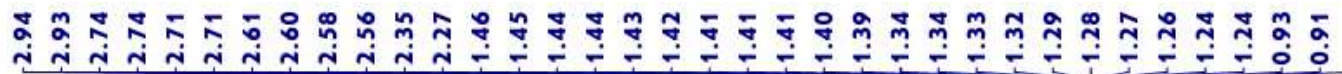<smiles>CCC[C@H]1CC(=O)OC(C)=C1C(C)=O</smiles>

3i

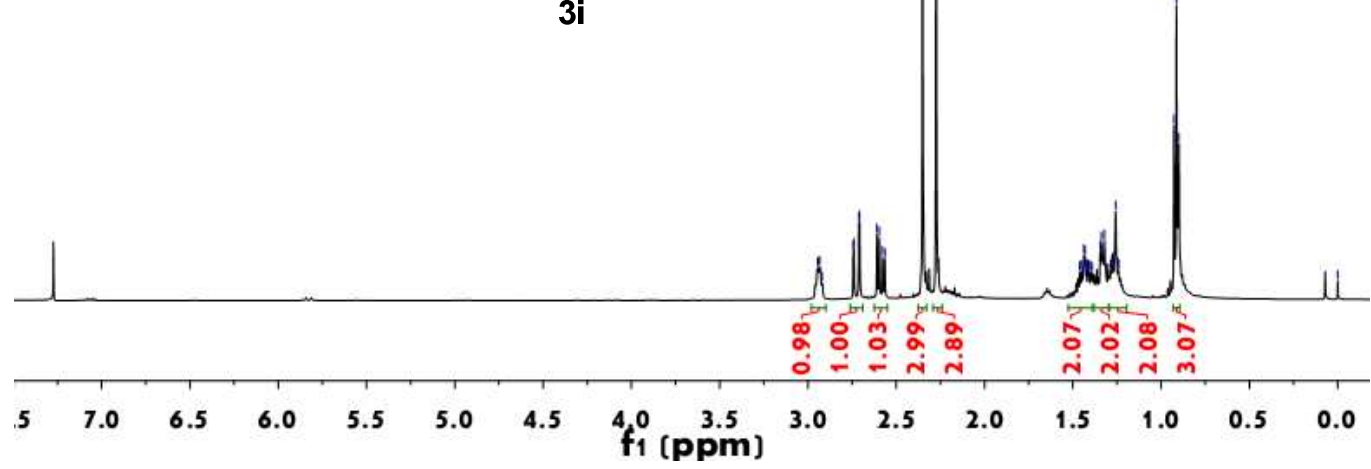<smiles>CCC[C@H]1CC(=O)OC(C)=C1C(C)=O</smiles>

3i
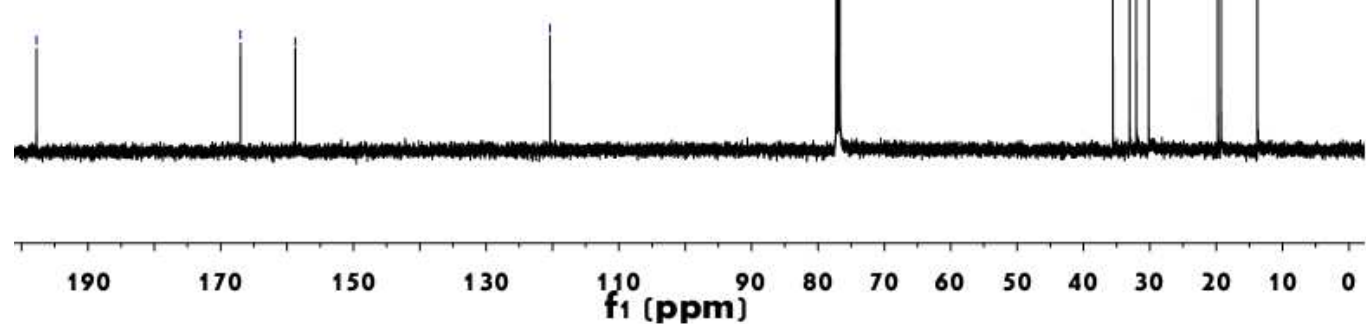

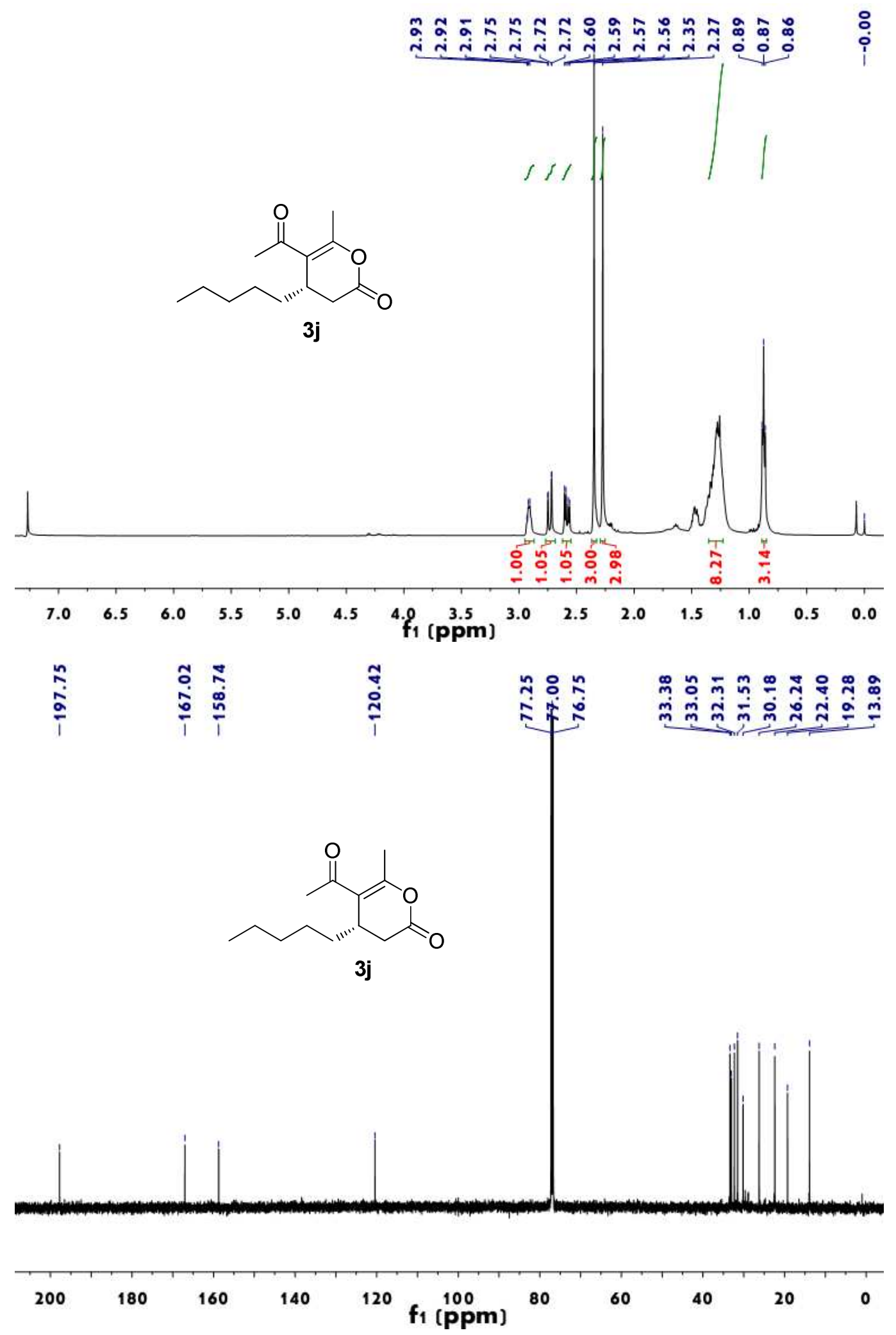


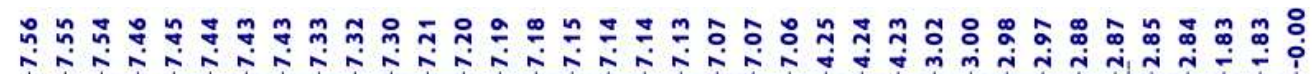
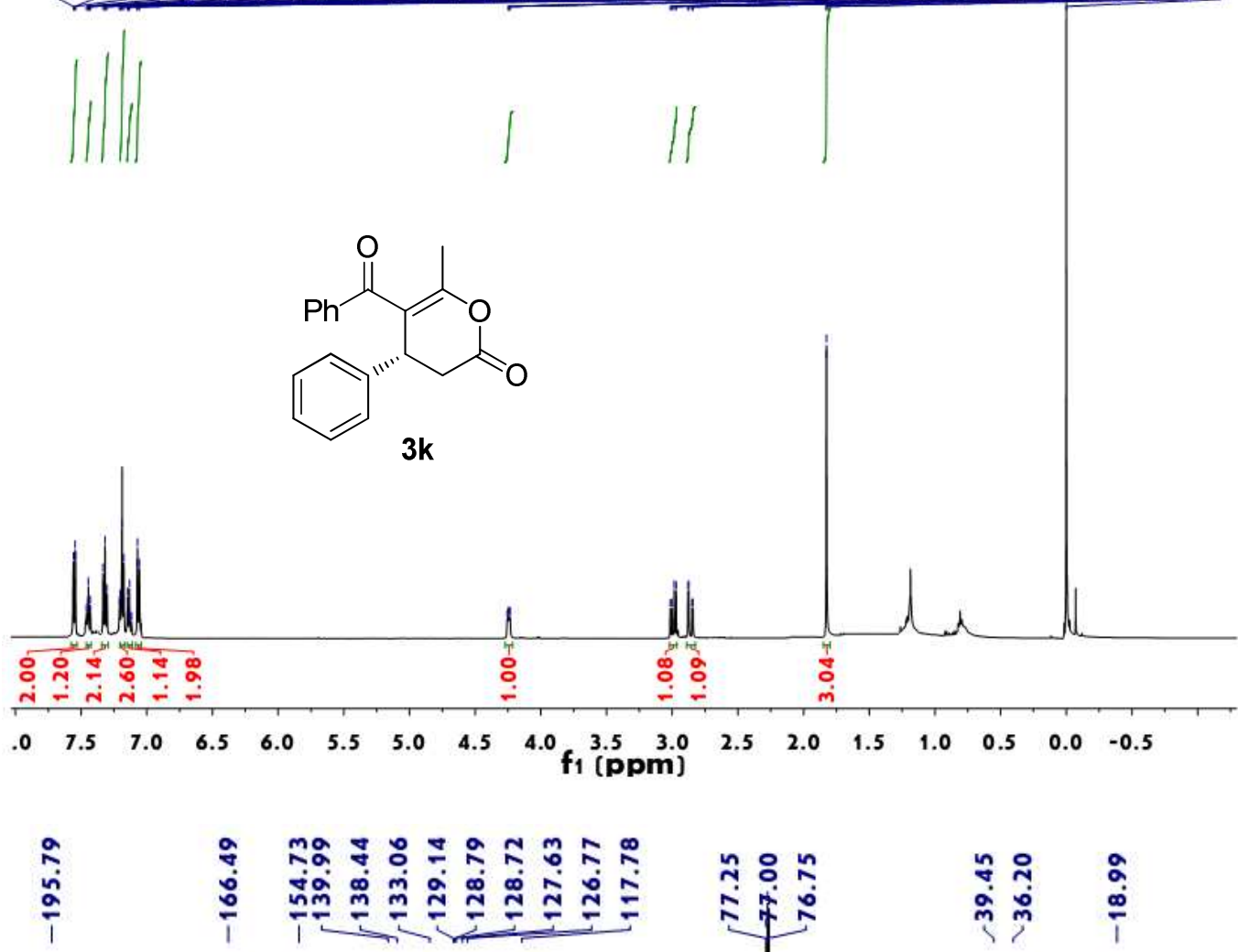

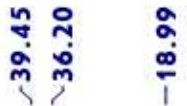<smiles>CC1=C(C(=O)c2ccccc2)[C@@H](c2ccccc2)CC(=O)O1</smiles>
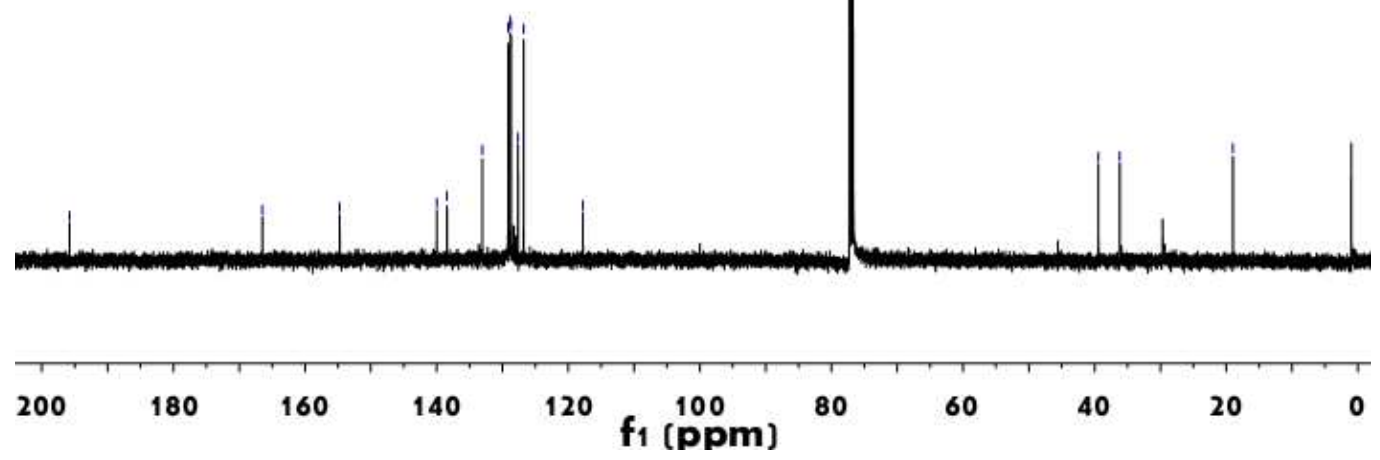


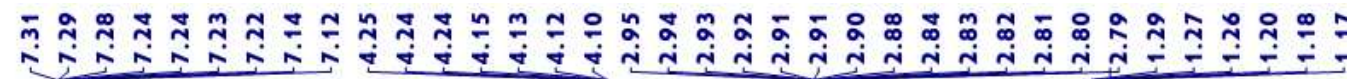

111

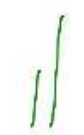

11<smiles>CCOC(=O)C1=C(CC)OC(=O)C[C@H]1c1ccccc1</smiles>

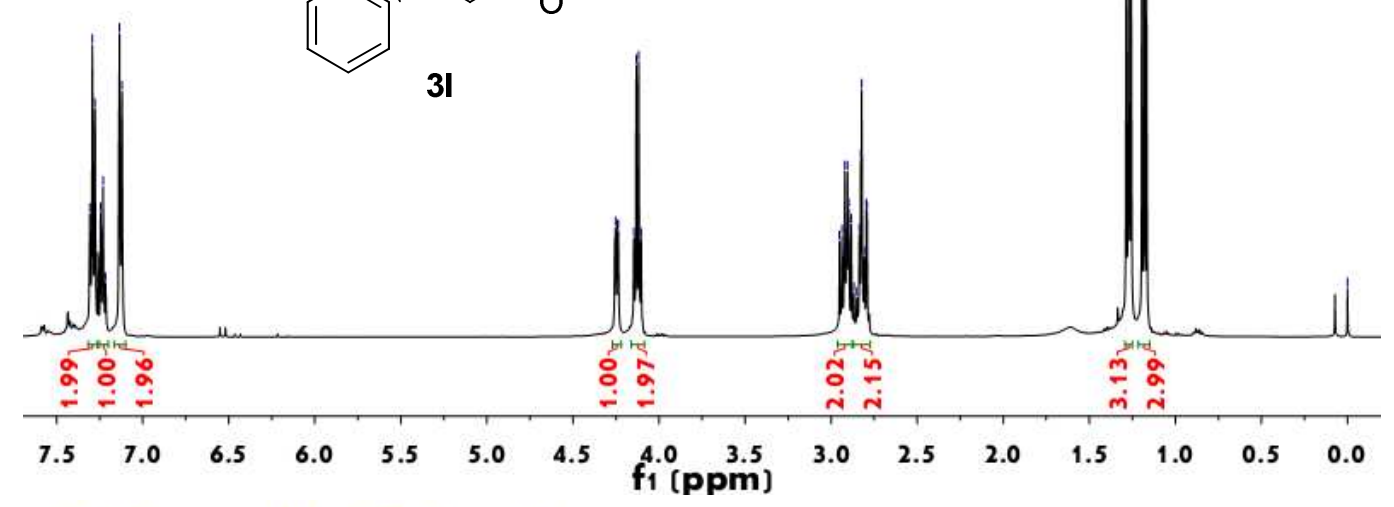

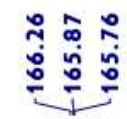

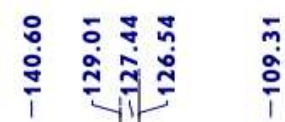

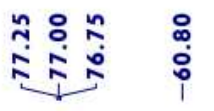

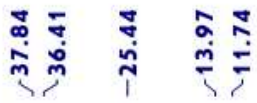
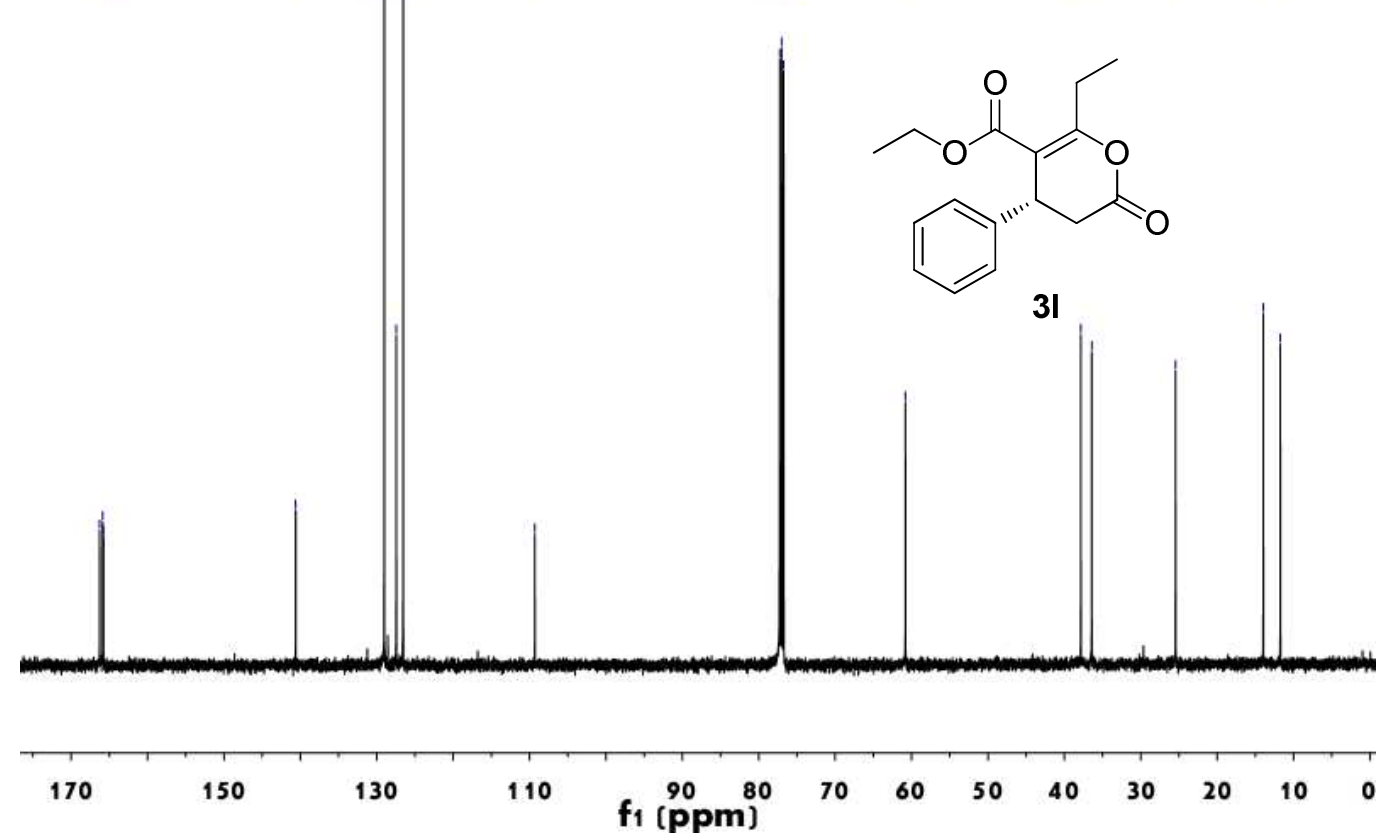


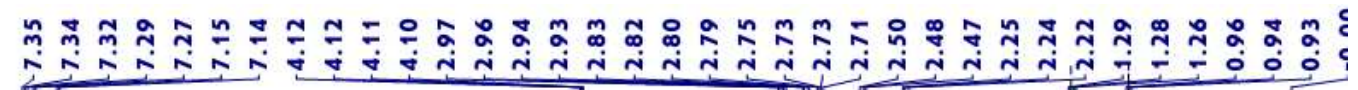

11
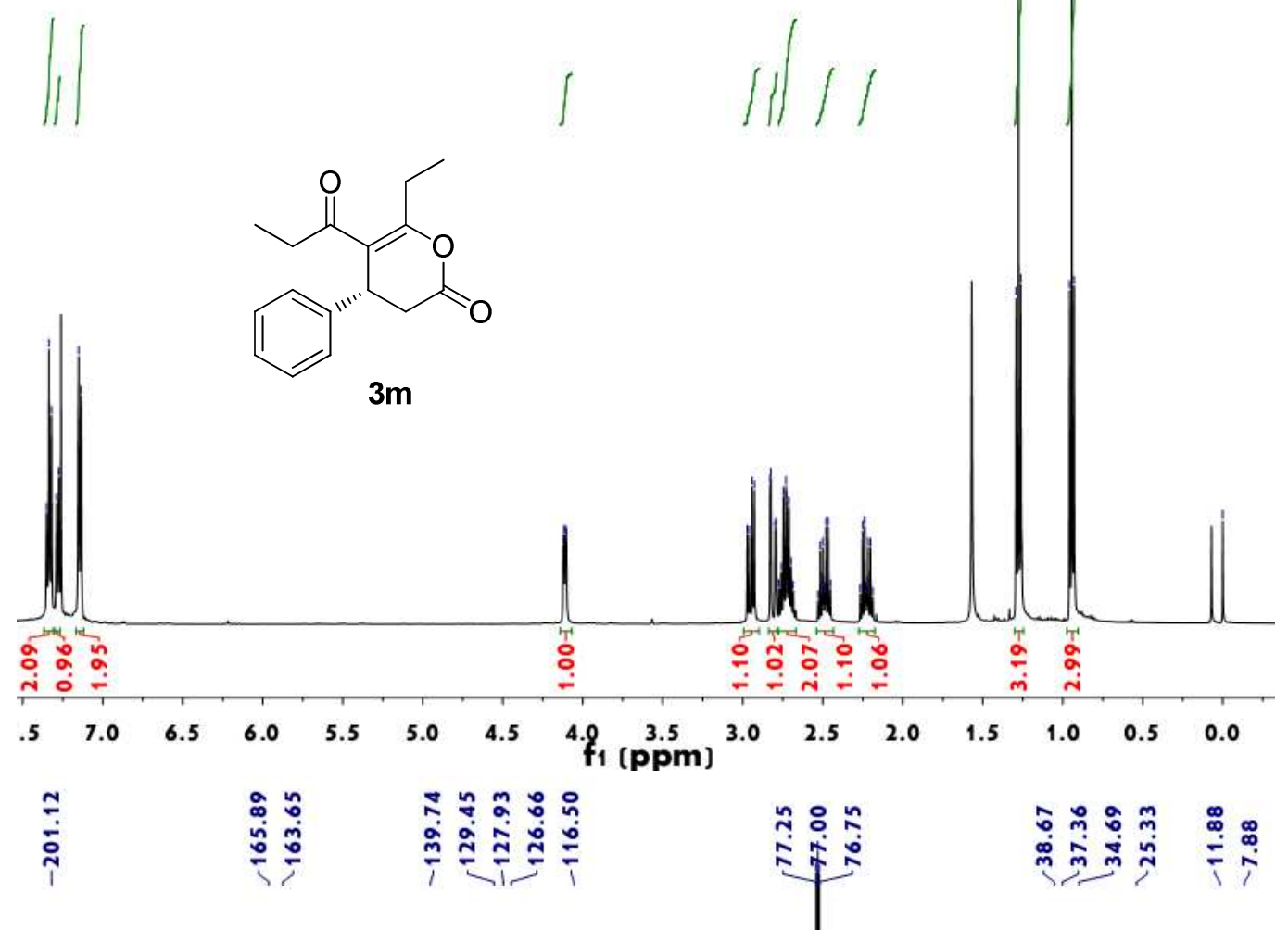<smiles>CCC(=O)C1=C(CC)OC(=O)C[C@H]1c1ccccc1</smiles>
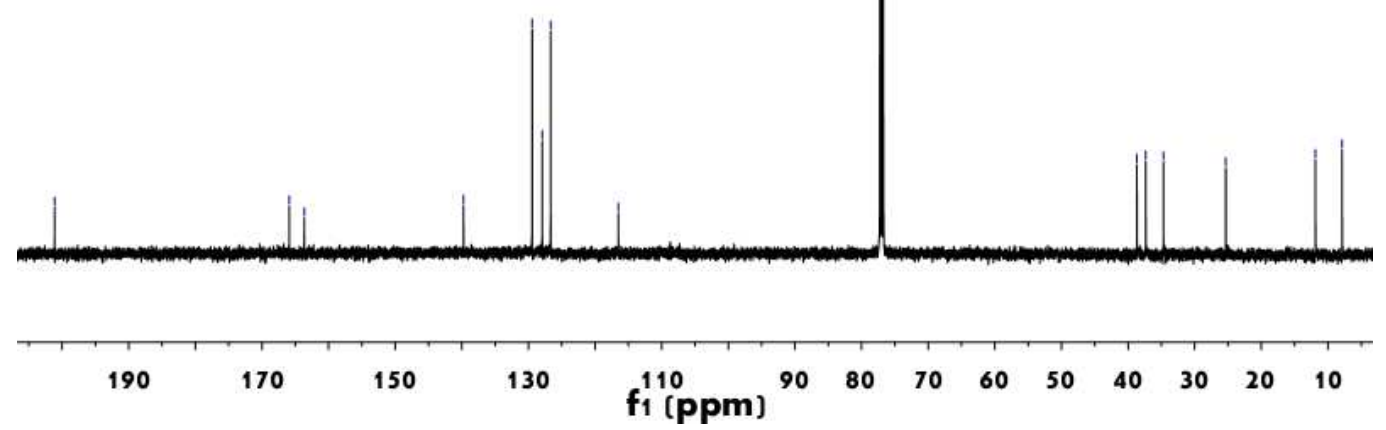

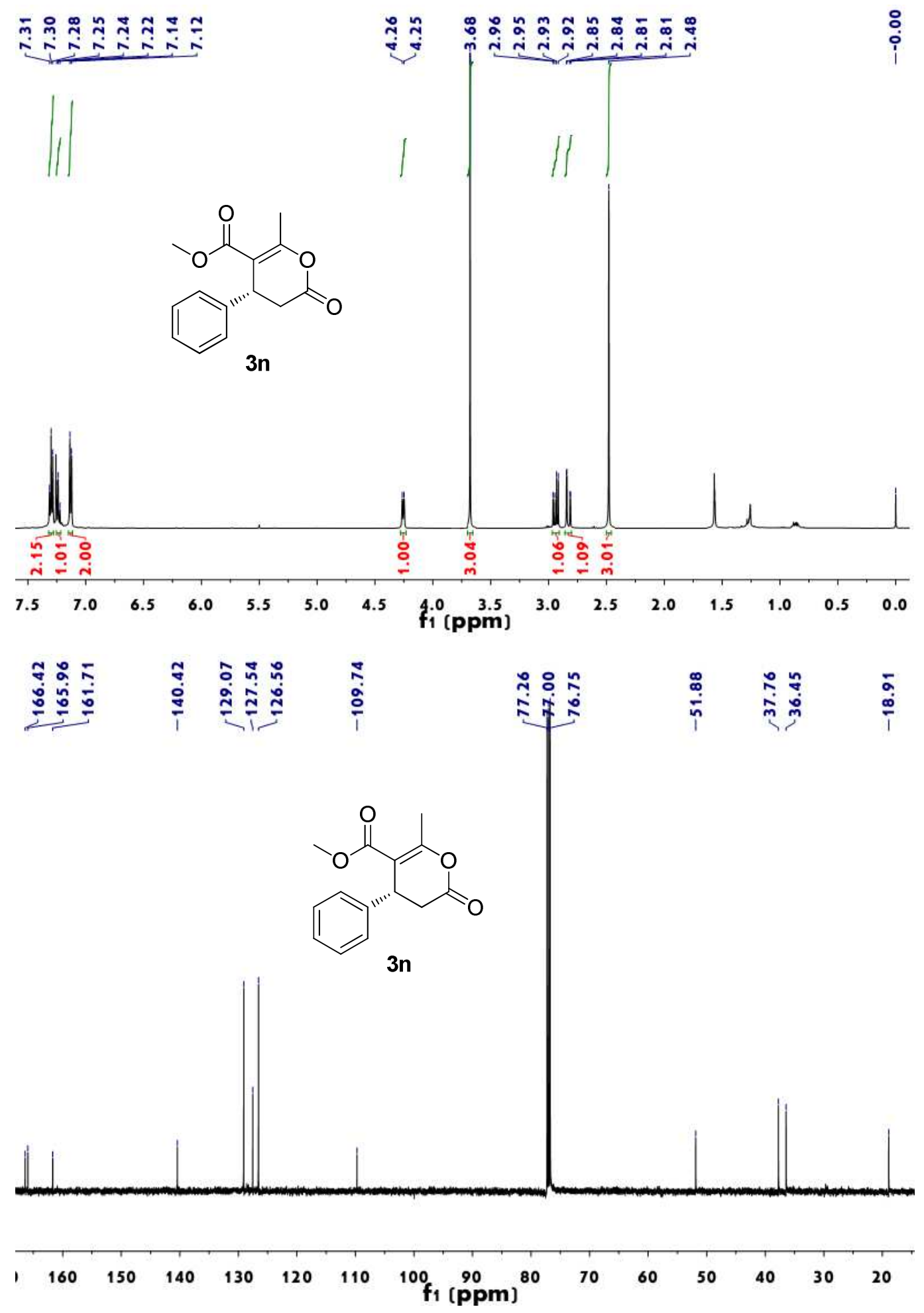


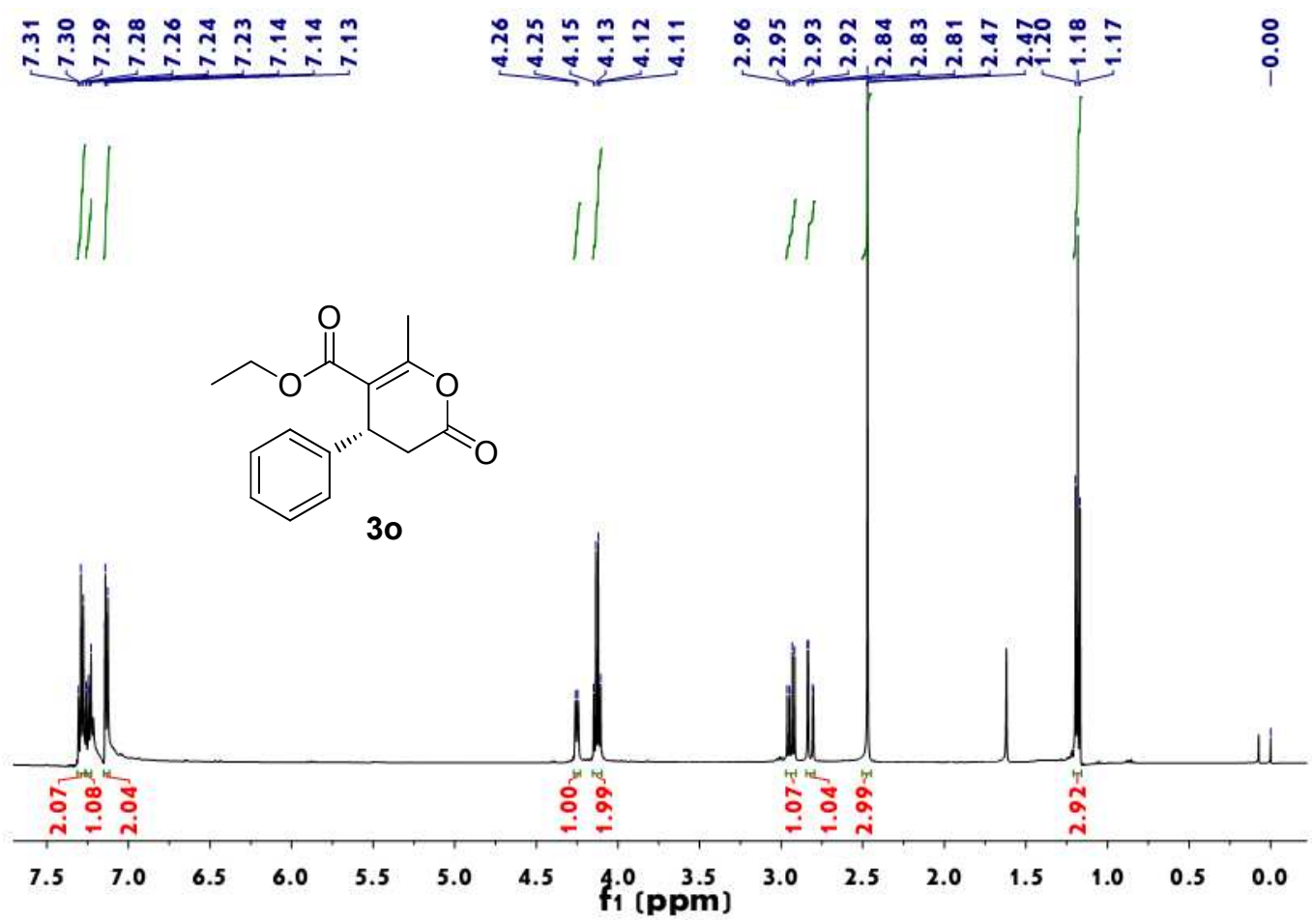

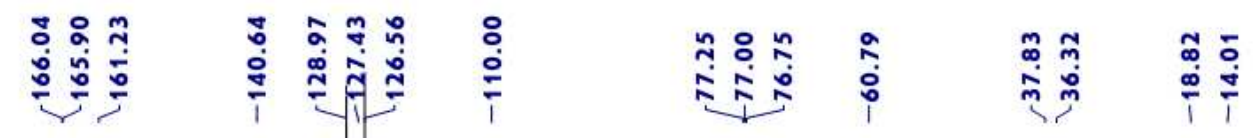
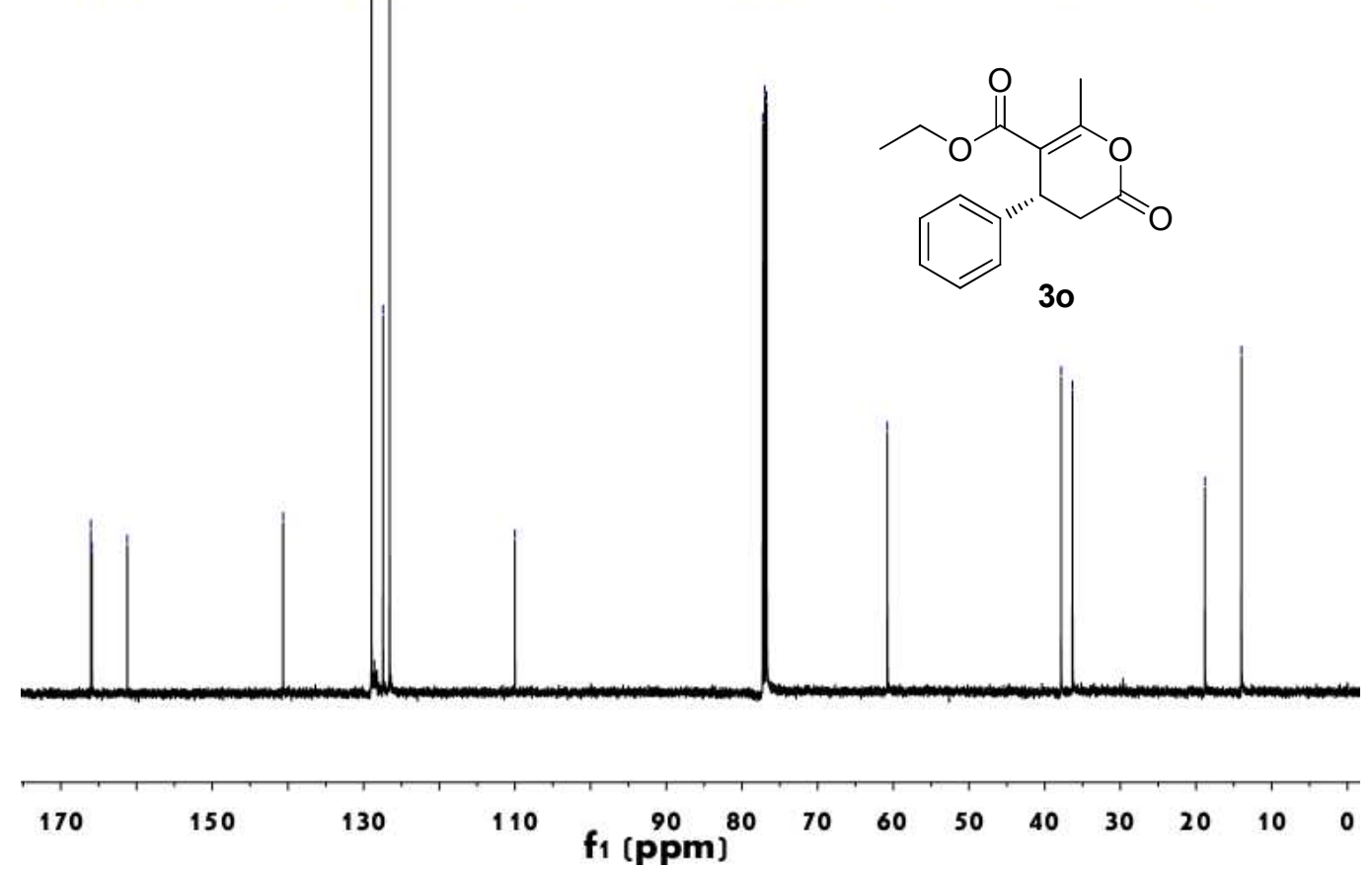


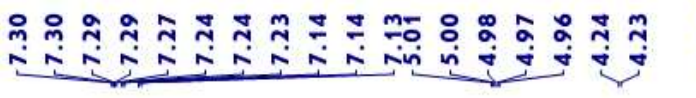

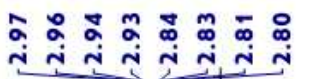

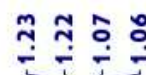

$\| 1$<smiles>C=CCC</smiles>

$\iint$<smiles>CC1=C(C(=O)OC(C)C)[C@H](c2ccccc2)CC(=O)O1</smiles>

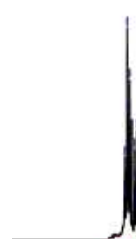

$3 p$

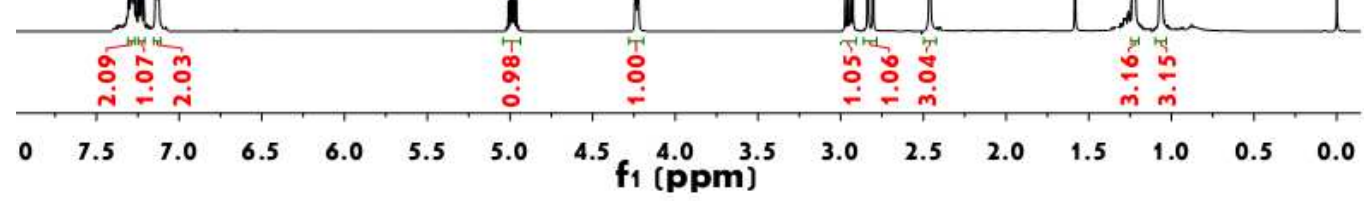

ำ จ

它官

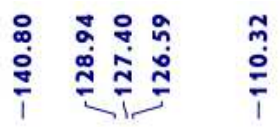

空

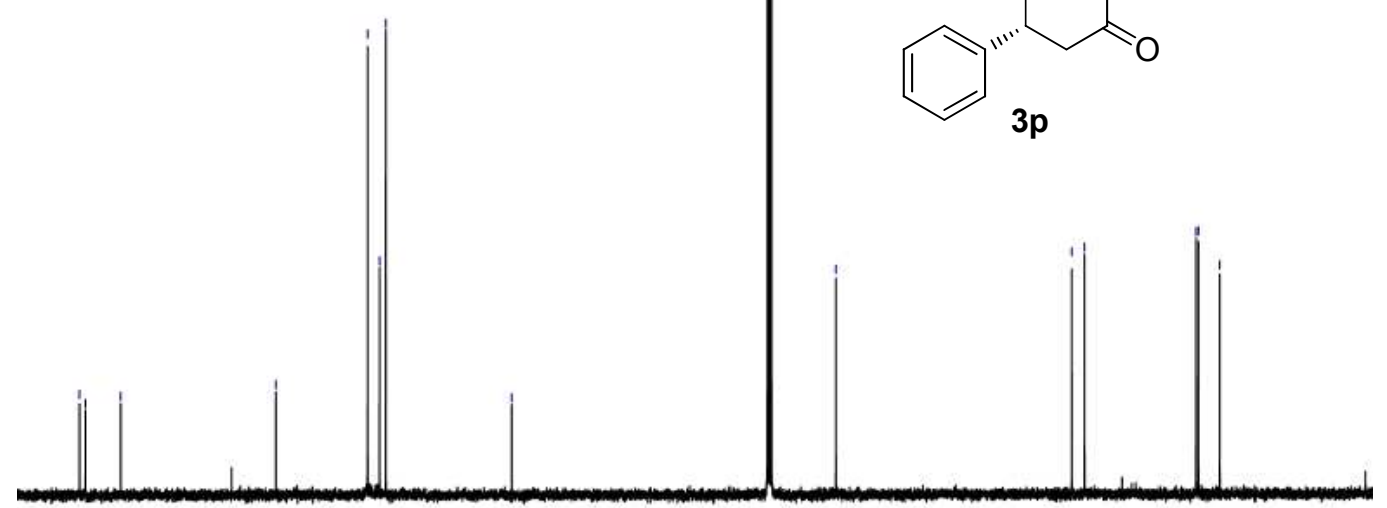<smiles>CC1=C(C(=O)OC(C)C)[C@H](c2ccccc2)CC(=O)O1</smiles>

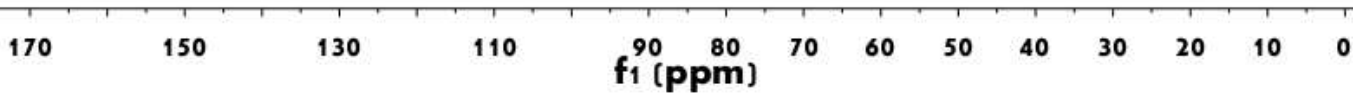



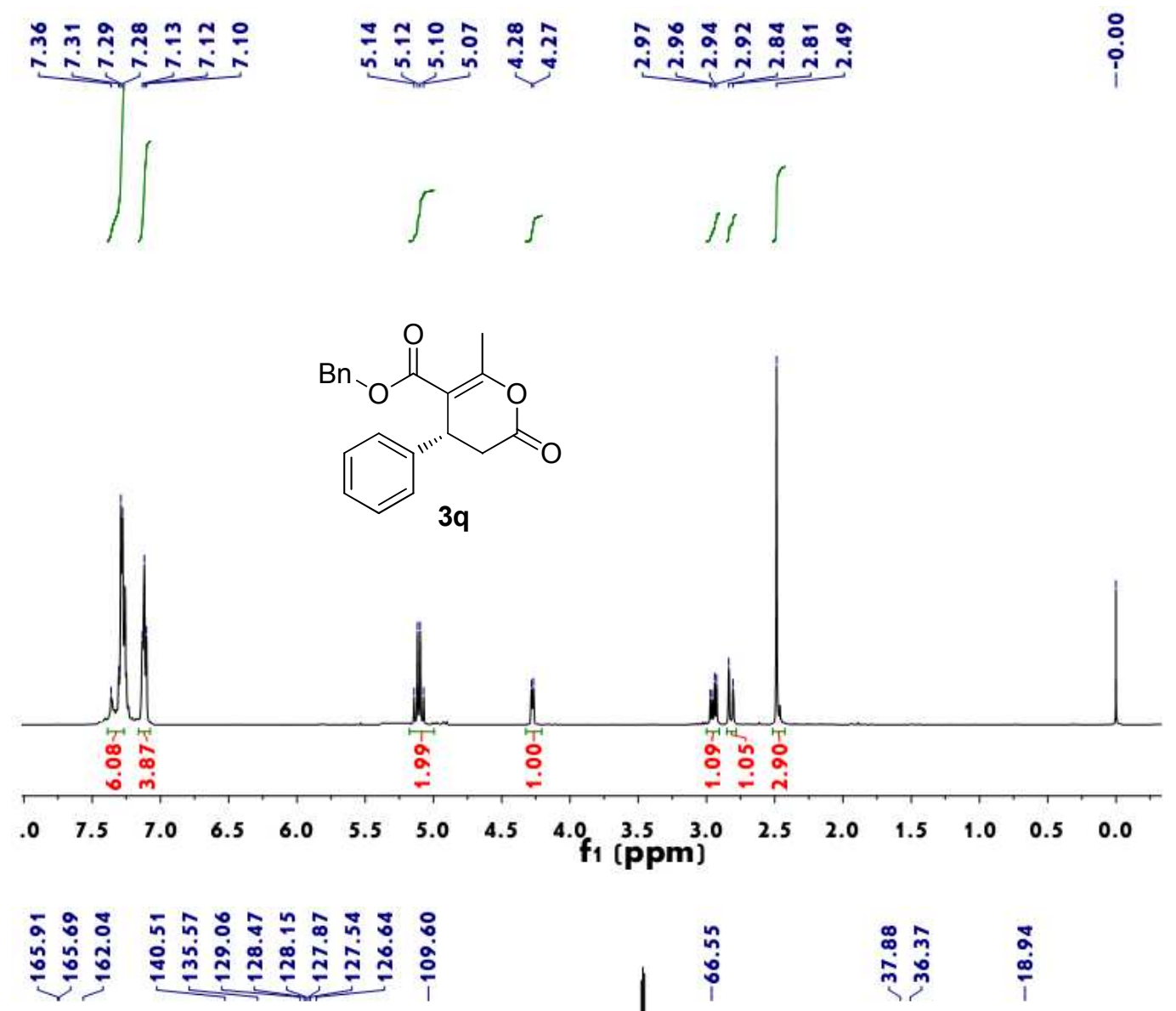<smiles>CC1=C(C(=O)OCc2ccccc2)[C@@H](c2ccccc2)CC(=O)O1</smiles>
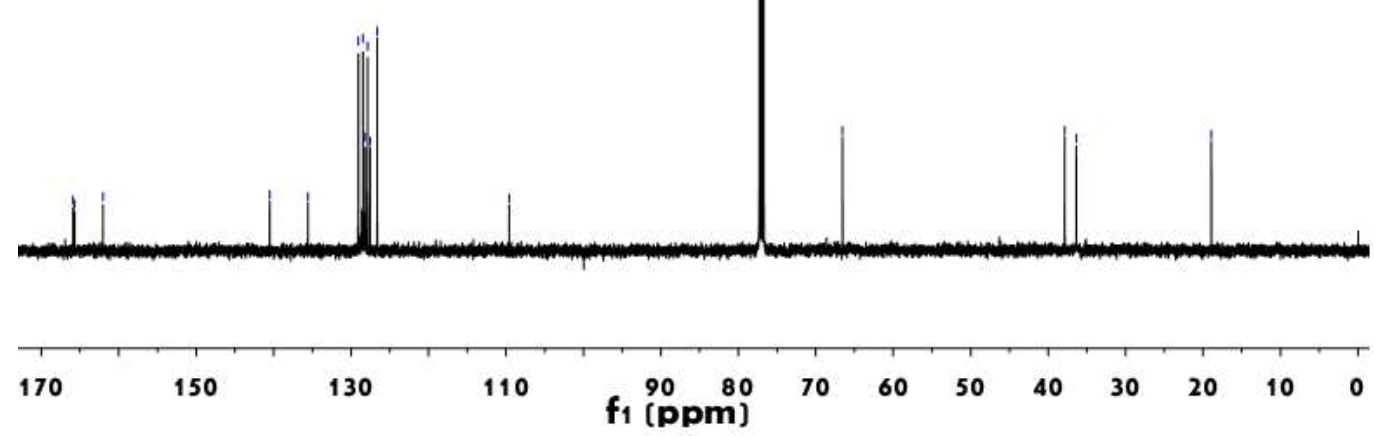


\section{Chiral HPLC spectra of 3.}<smiles>CC(=O)C1=C(C)OC(=O)C[C@H]1c1ccccc1</smiles>

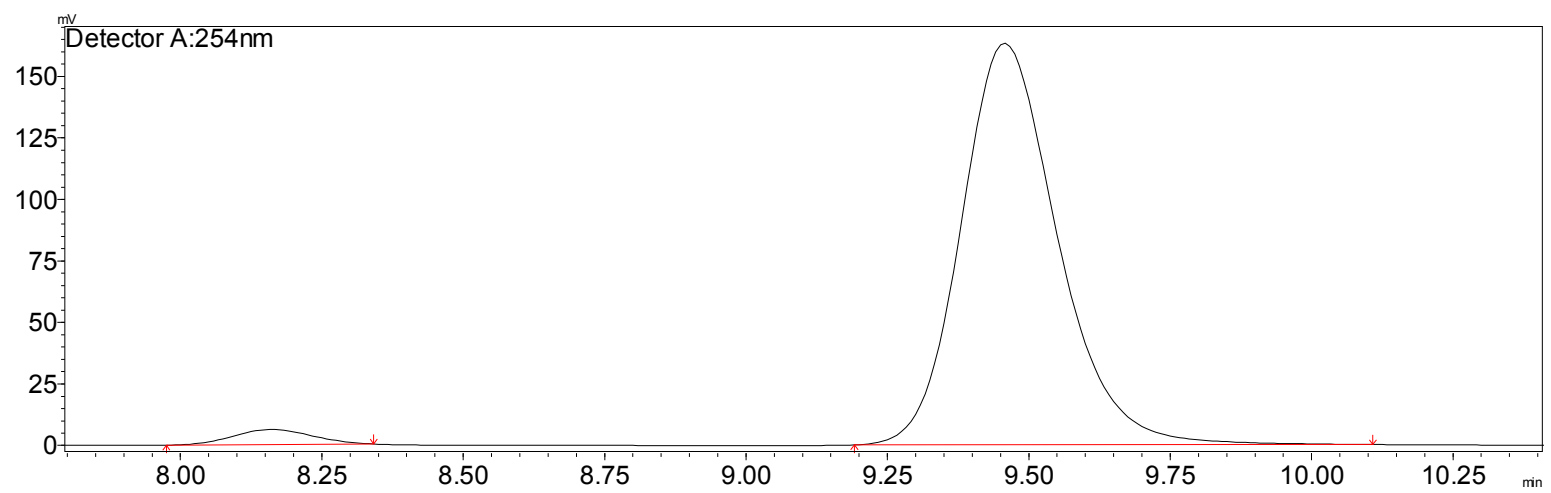

\begin{tabular}{|c|c|c|c|c|c|}
\hline Peak\# & Ret. Time & Area & Height & Area \% & Height \% \\
\hline 1 & 8.157 & 60028 & 6170 & 3.012 & 3.642 \\
\hline 2 & 9.453 & 1932969 & 163213 & 96.988 & 96.358 \\
\hline Total & & 1992997 & 169383 & 100.000 & 100.000 \\
\hline
\end{tabular}

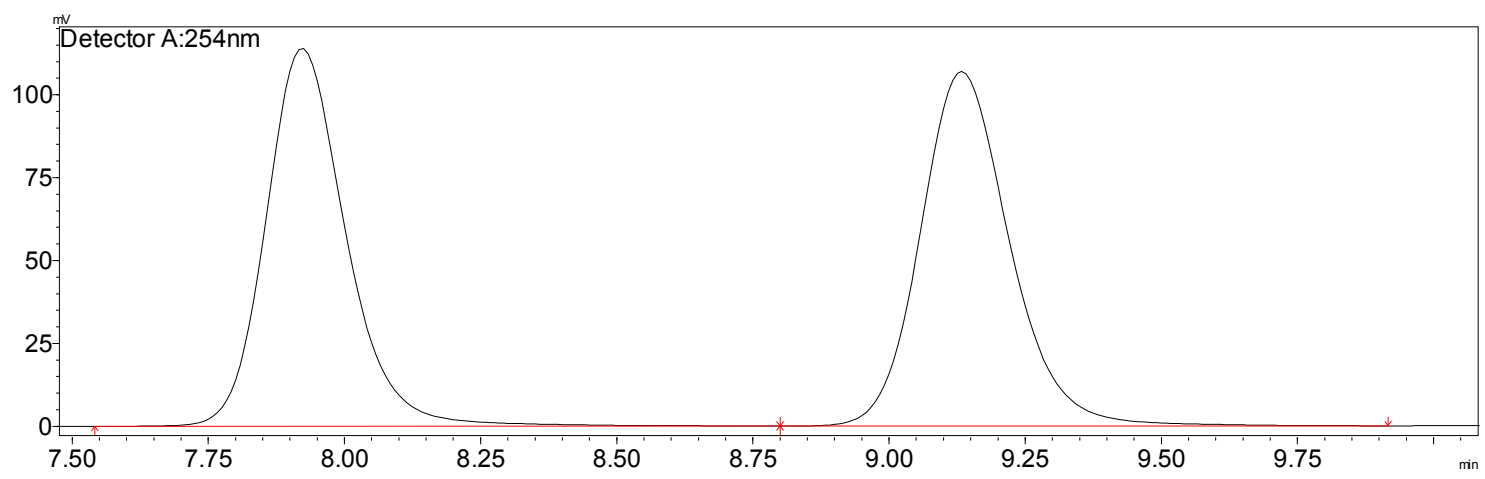

\begin{tabular}{|c|c|c|c|c|c|}
\hline Peak\# & Ret. Time & Area & Height & Area \% & Height \% \\
\hline 1 & 7.918 & 1164877 & 113879 & 48.870 & 51.558 \\
\hline 2 & 9.129 & 1218746 & 106999 & 51.130 & 48.442 \\
\hline Total & & 2383623 & 220878 & 100.000 & 100.000 \\
\hline
\end{tabular}


<smiles>COc1ccc([C@H]2CC(=O)OC(C)=C2C(C)=O)cc1</smiles>

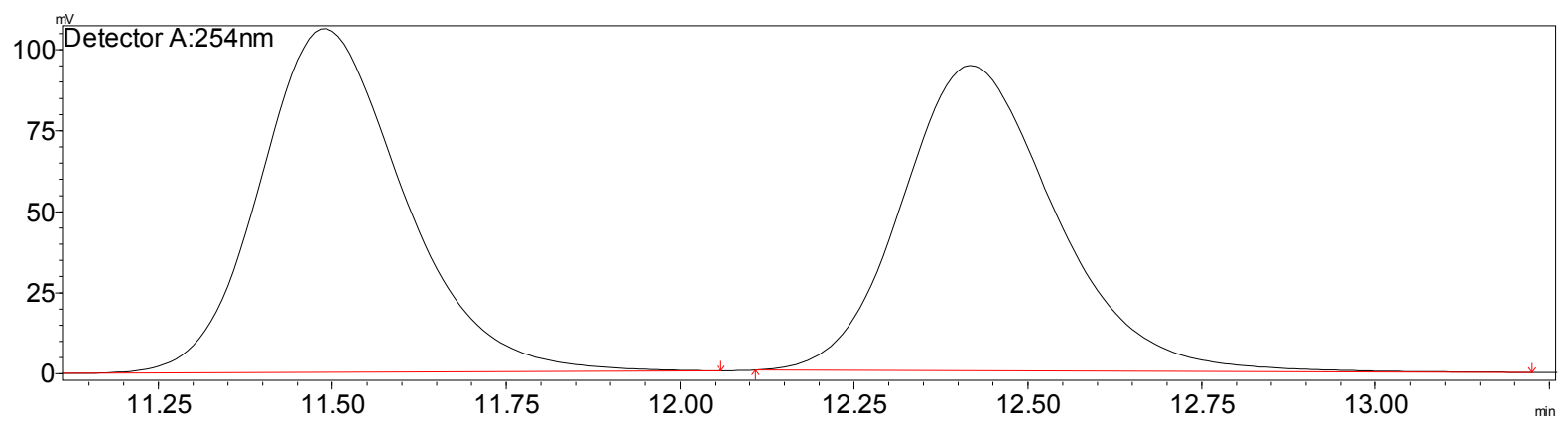

\begin{tabular}{|c|c|c|c|c|c|}
\hline Peak\# & Ret. Time & Area & Height & Area \% & Height \% \\
\hline 1 & 11.485 & 1524534 & 106006 & 51.370 & 52.954 \\
\hline 2 & 12.414 & 1443194 & 94178 & 48.630 & 47.046 \\
\hline Total & & 2967728 & 200184 & 100.000 & 100.000 \\
\hline
\end{tabular}

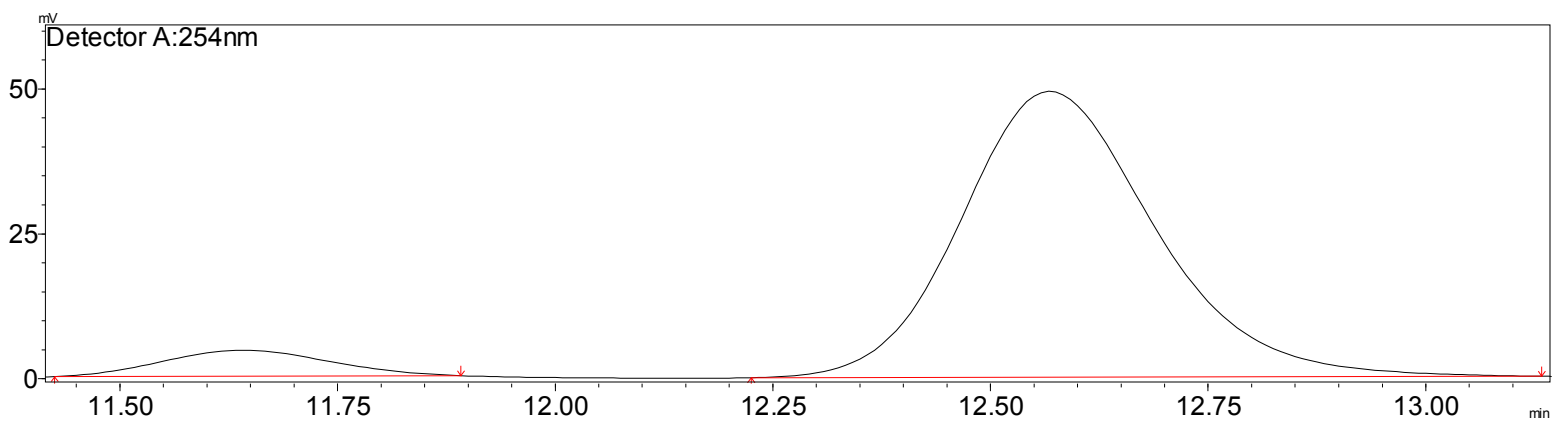

\begin{tabular}{|c|c|c|c|c|c|}
\hline Peak\# & Ret. Time & Area & Height & Area \% & Height \% \\
\hline 1 & 11.637 & 59808 & 4510 & 7.248 & 8.380 \\
\hline 2 & 12.564 & 765344 & 49307 & 92.752 & 91.620 \\
\hline Total & & 825151 & 53817 & 100.000 & 100.000 \\
\hline
\end{tabular}


<smiles>CC(=O)C1=C(C)OC(=O)C[C@H]1c1ccc(F)cc1</smiles>

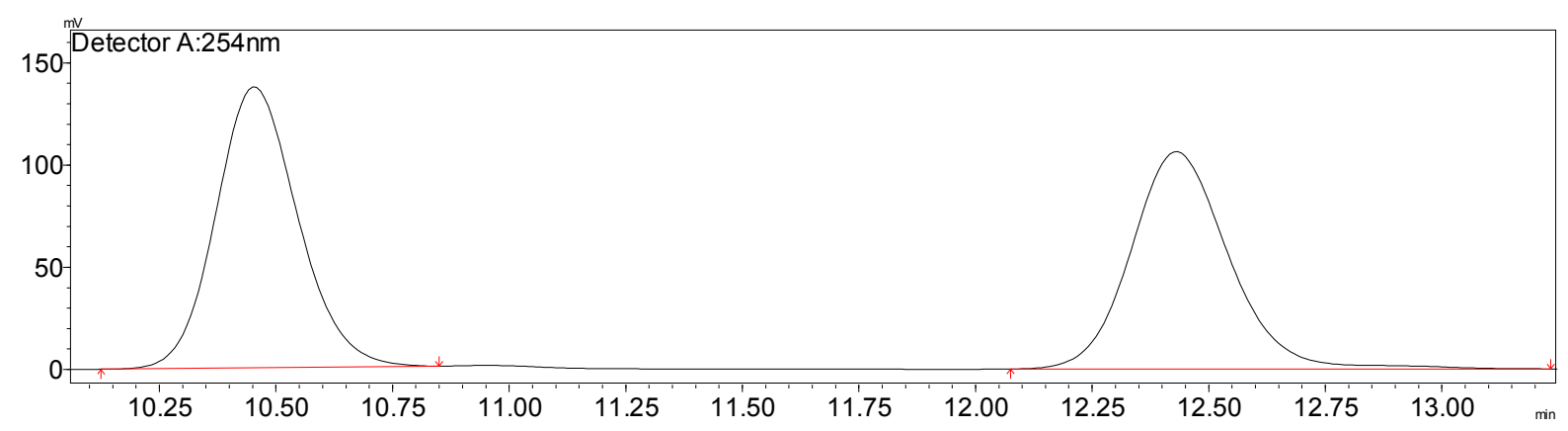

\begin{tabular}{|c|c|c|c|c|c|}
\hline Peak\# & Ret. Time & Area & Height & Area \% & Height \% \\
\hline 1 & 10.449 & 1681421 & 137477 & 51.934 & 56.388 \\
\hline 2 & 12.426 & 1556203 & 106329 & 48.066 & 43.612 \\
\hline Total & & 3237624 & 243806 & 100.000 & 100.000 \\
\hline
\end{tabular}

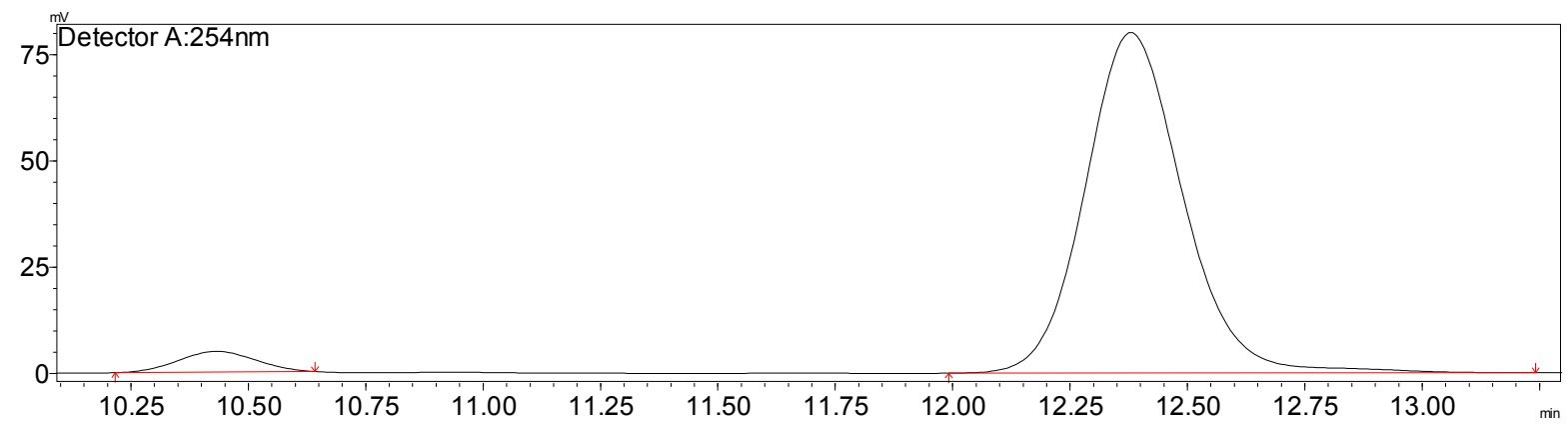

\begin{tabular}{|c|c|c|c|c|c|}
\hline Peak\# & Ret. Time & Area & Height & Area \% & Height \% \\
\hline 1 & 10.428 & 56067 & 4866 & 4.600 & 5.725 \\
\hline 2 & 12.375 & 1162915 & 80141 & 95.400 & 94.275 \\
\hline Total & & 1218982 & 85007 & 100.000 & 100.000 \\
\hline
\end{tabular}


<smiles>CC(=O)C1=C(C)OC(=O)C[C@H]1c1ccc(Cl)cc1</smiles>

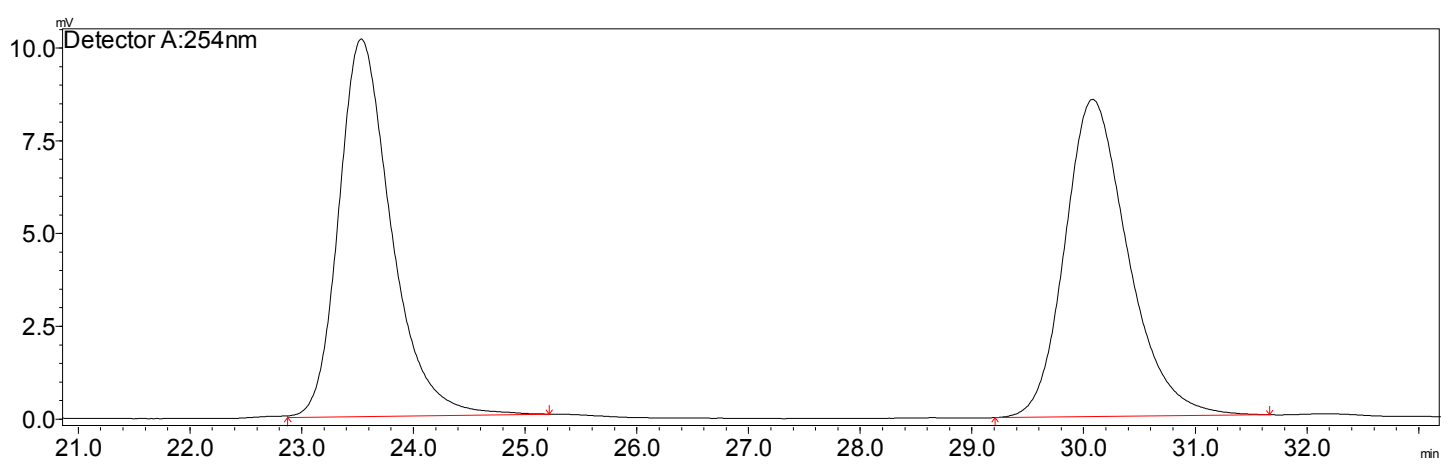

\begin{tabular}{|c|c|c|c|c|c|}
\hline Peak\# & Ret. Time & Area & Height & Area \% & Height \% \\
\hline 1 & 23.528 & 329964 & 10164 & 49.563 & 54.312 \\
\hline 2 & 30.076 & 335776 & 8550 & 50.437 & 45.688 \\
\hline Total & & 665740 & 18715 & 100.000 & 100.000 \\
\hline
\end{tabular}

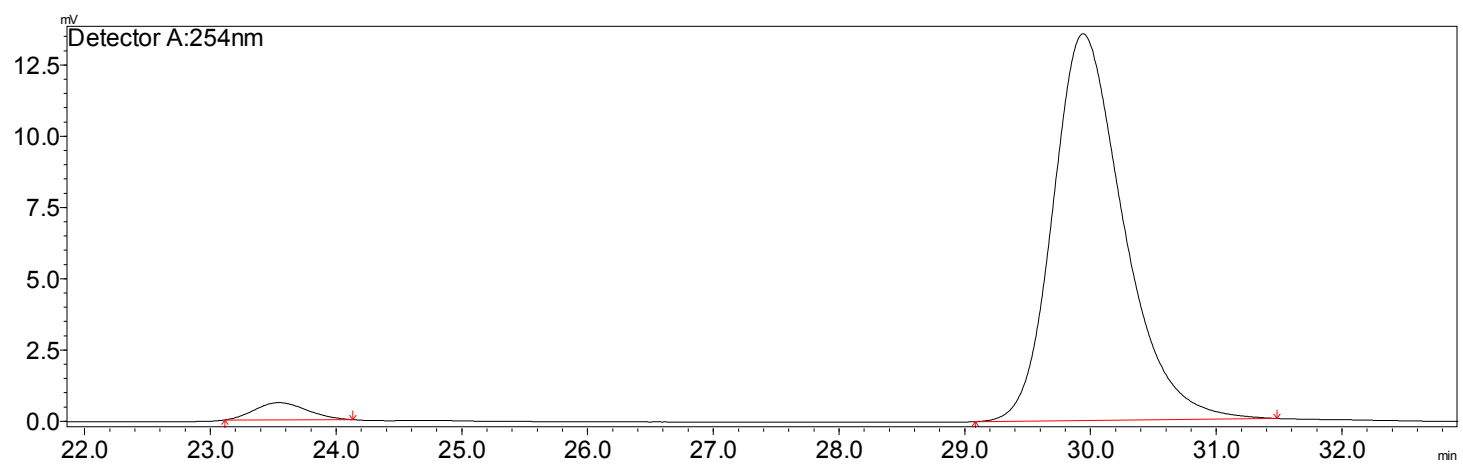

\begin{tabular}{|c|c|c|c|c|c|}
\hline Peak\# & Ret. Time & Area & Height & Area \% & Height \% \\
\hline 1 & 23.542 & 17457 & 605 & 3.192 & 4.269 \\
\hline 2 & 29.937 & 529373 & 13577 & 96.808 & 95.731 \\
\hline Total & & 546829 & 14183 & 100.000 & 100.000 \\
\hline
\end{tabular}


<smiles>CC(=O)C1=C(C)OC(=O)C[C@H]1c1ccc([N+](=O)[O-])cc1</smiles>

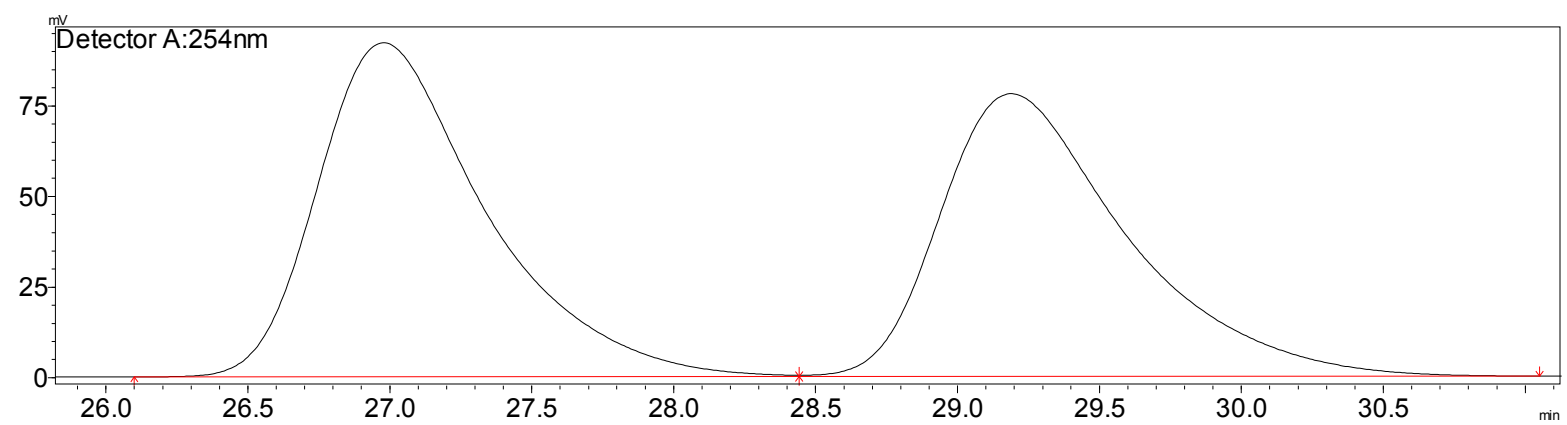

\begin{tabular}{|c|c|c|c|c|c|}
\hline Peak\# & Ret. Time & Area & Height & Area \% & Height \% \\
\hline 1 & 26.974 & 3804075 & 92129 & 51.649 & 54.159 \\
\hline 2 & 29.185 & 3561234 & 77978 & 48.351 & 45.841 \\
\hline Total & & 7365309 & 170106 & 100.000 & 100.000 \\
\hline
\end{tabular}

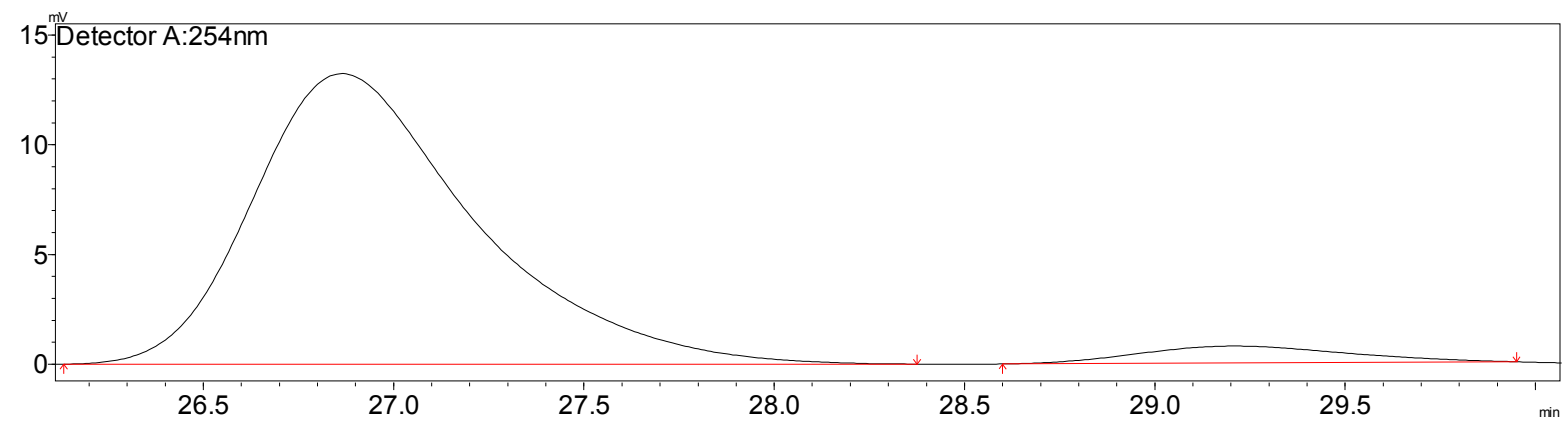

\begin{tabular}{|c|c|c|c|c|c|}
\hline Peak\# & Ret. Time & Area & Height & Area \% & Height \% \\
\hline 1 & 26.861 & 537490 & 13242 & 94.824 & 94.460 \\
\hline 2 & 29.206 & 29340 & 777 & 5.176 & 5.540 \\
\hline Total & & 566830 & 14018 & 100.000 & 100.000 \\
\hline
\end{tabular}


<smiles>COc1ccccc1[C@@H]1CC(=O)OC(C)=C1C(C)=O</smiles>

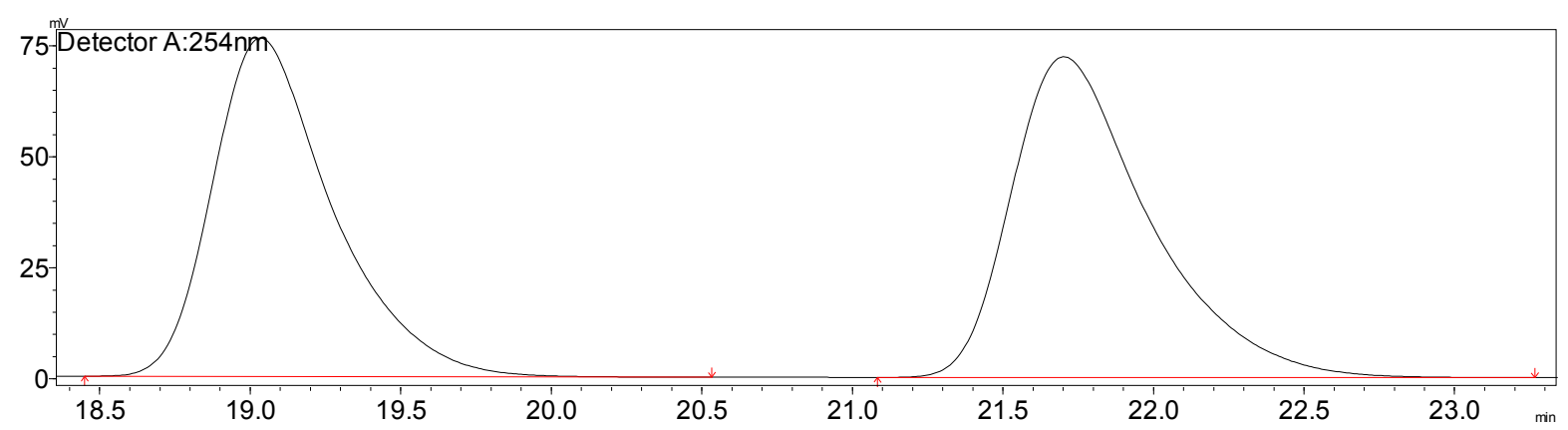

\begin{tabular}{|c|c|c|c|c|c|}
\hline Peak\# & Ret. Time & Area & Height & Area \% & Height \% \\
\hline 1 & 19.030 & 2116115 & 76257 & 47.945 & 51.352 \\
\hline 2 & 21.698 & 2297504 & 72241 & 52.055 & 48.648 \\
\hline Total & & 4413619 & 148498 & 100.000 & 100.000 \\
\hline
\end{tabular}

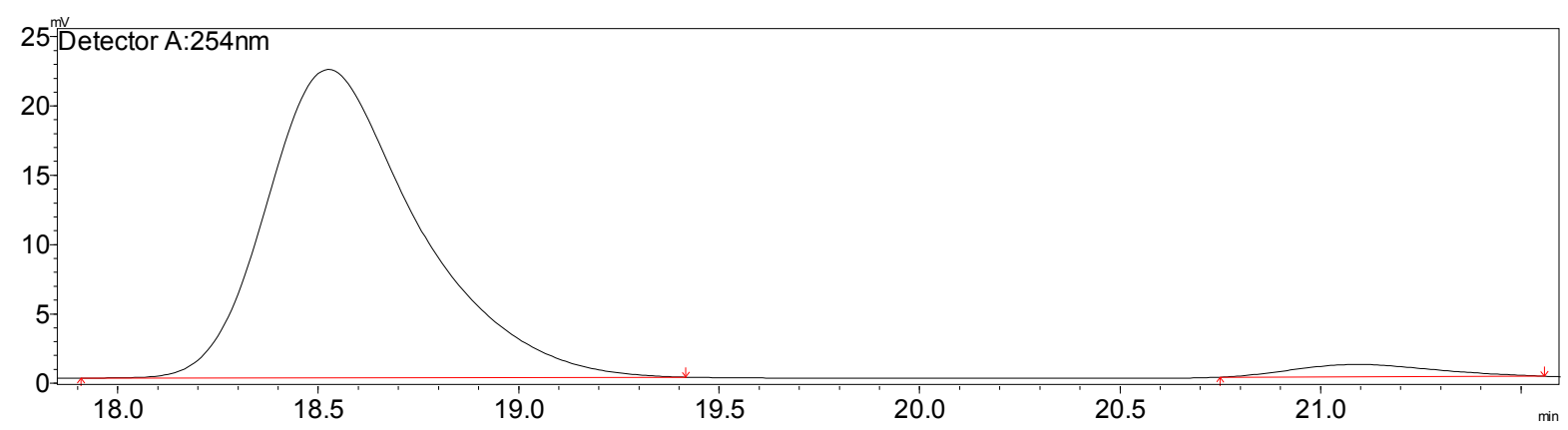

\begin{tabular}{|l|l|l|l|l|l|}
\hline Peak\# & Ret. Time & Area & Height & Area \% & Height \% \\
\hline 1 & 18.521 & 583296 & 22234 & 96.437 & 96.160 \\
\hline 2 & 21.089 & 21550 & 888 & 3.563 & 3.840 \\
\hline Total & & 604845 & 23122 & 100.000 & 100.000 \\
\hline
\end{tabular}


<smiles>CC(=O)C1=C(C)OC(=O)C[C@H]1c1ccccc1[N+](=O)[O-]</smiles>

$3 g$

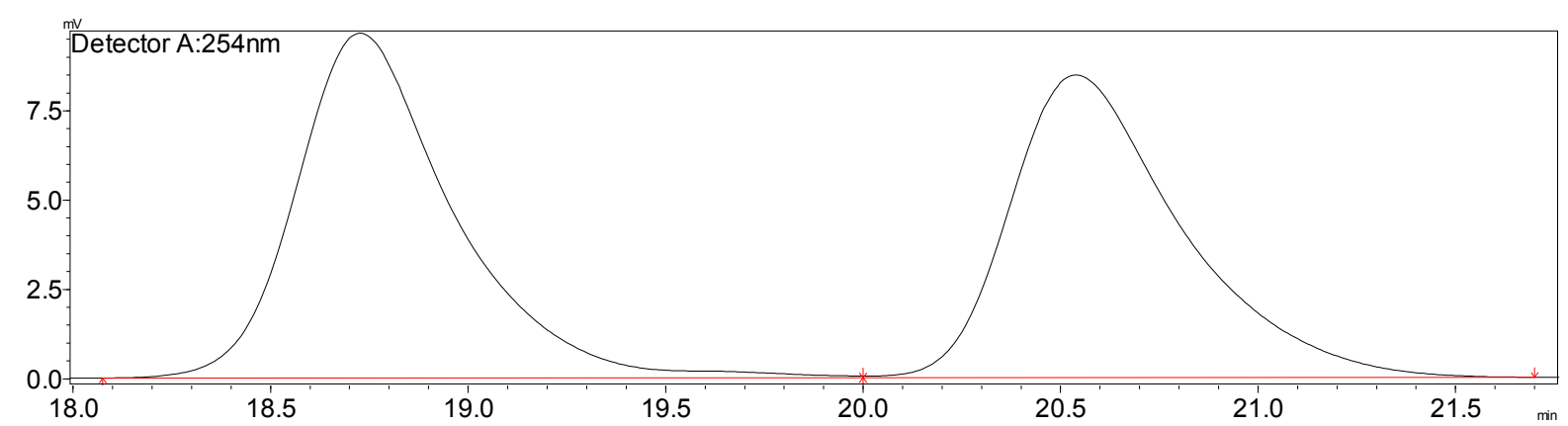

\begin{tabular}{|c|c|c|c|c|c|}
\hline Peak\# & Ret. Time & Area & Height & Area \% & Height \% \\
\hline 1 & 18.722 & 267238 & 9645 & 51.162 & 53.261 \\
\hline 2 & 20.535 & 255096 & 8464 & 48.838 & 46.739 \\
\hline Total & & 522334 & 18110 & 100.000 & 100.000 \\
\hline
\end{tabular}

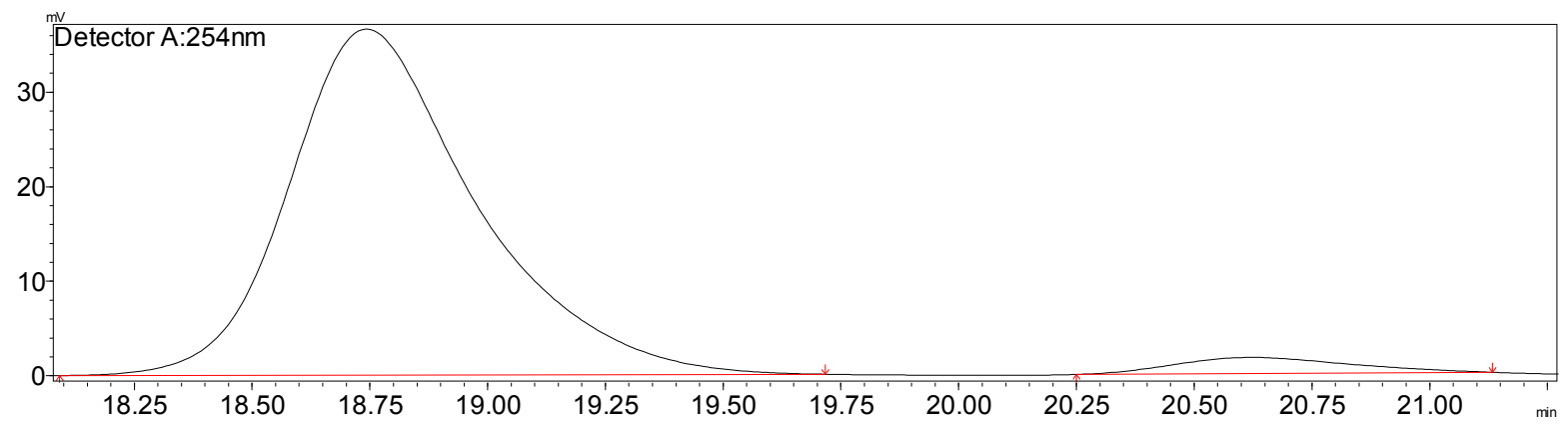

\begin{tabular}{|c|c|c|c|c|c|}
\hline Peak\# & Ret. Time & Area & Height & Area \% & Height \% \\
\hline 1 & 18.739 & 1012899 & 36604 & 95.842 & 95.548 \\
\hline 2 & 20.617 & 43942 & 1706 & 4.158 & 4.452 \\
\hline Total & & 1056841 & 38309 & 100.000 & 100.000 \\
\hline
\end{tabular}


<smiles>CC(=O)C1=C(C)OC(=O)C[C@H]1c1ccco1</smiles>

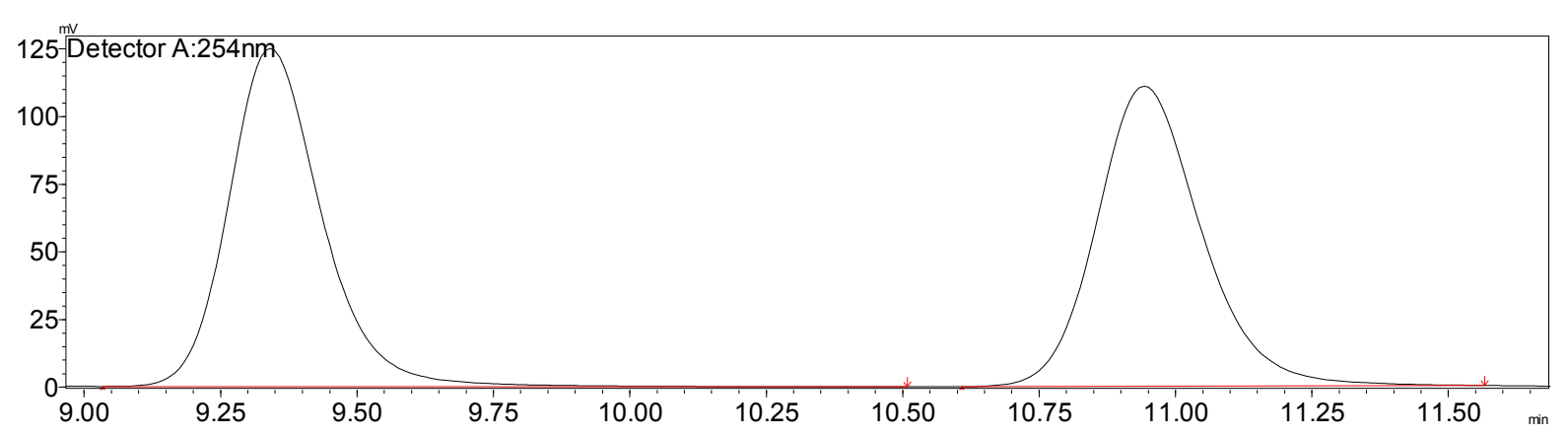

\begin{tabular}{|c|c|c|c|c|c|}
\hline Peak\# & Ret. Time & Area & Height & Area \% & Height \% \\
\hline 1 & 9.337 & 1483471 & 124974 & 50.027 & 52.969 \\
\hline 2 & 10.939 & 1481849 & 110966 & 49.973 & 47.031 \\
\hline Total & & 2965321 & 235940 & 100.000 & 100.000 \\
\hline
\end{tabular}

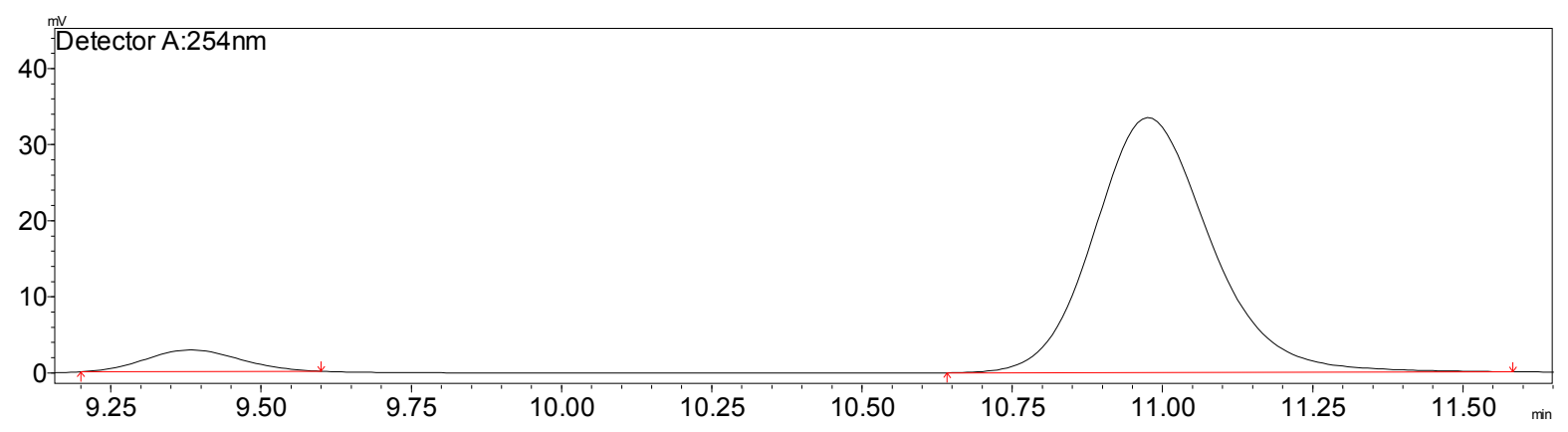

\begin{tabular}{|c|c|c|c|c|c|}
\hline Peak\# & Ret. Time & Area & Height & Area \% & Height \% \\
\hline 1 & 9.379 & 31211 & 2854 & 6.465 & 7.846 \\
\hline 2 & 10.972 & 451543 & 33520 & 93.535 & 92.154 \\
\hline Total & & 482754 & 36374 & 100.000 & 100.000 \\
\hline
\end{tabular}


<smiles>CCC[C@H]1CC(=O)OC(C)=C1C(C)=O</smiles>

3i

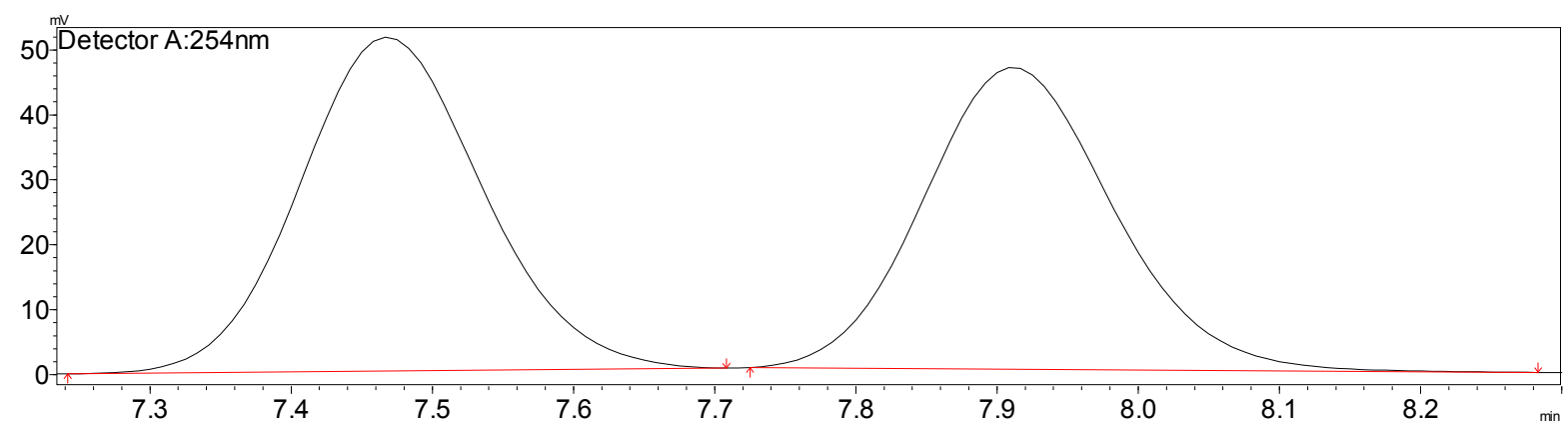

\begin{tabular}{|c|c|c|c|c|c|}
\hline Peak\# & Ret. Time & Area & Height & Area \% & Height \% \\
\hline 1 & 7.464 & 464712 & 51398 & 51.682 & 52.549 \\
\hline 2 & 7.907 & 434466 & 46412 & 48.318 & 47.451 \\
\hline Total & & 899178 & 97811 & 100.000 & 100.000 \\
\hline
\end{tabular}

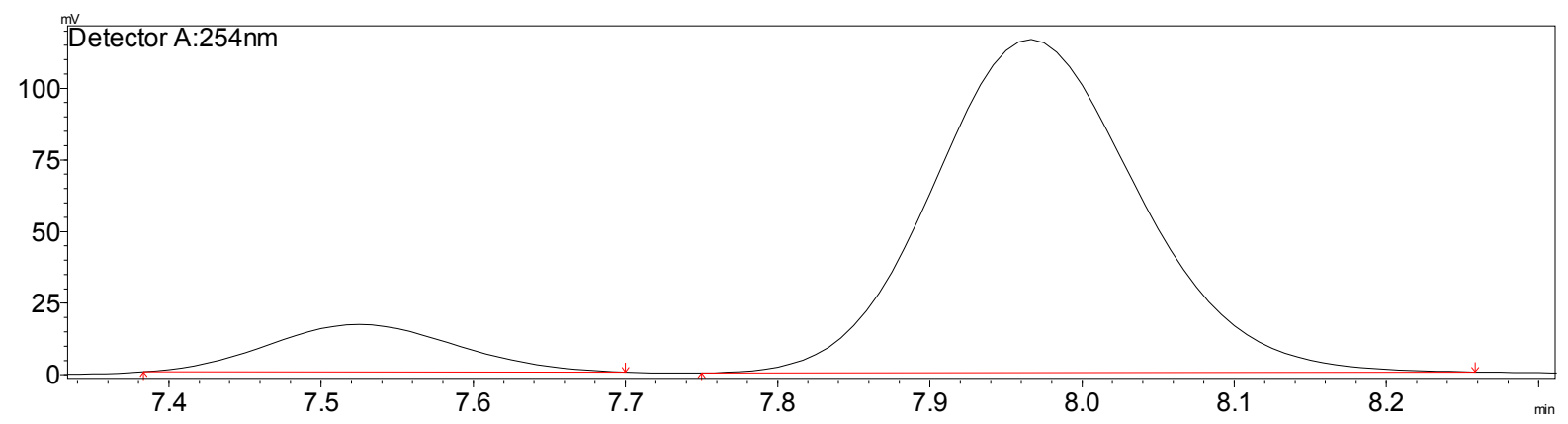

\begin{tabular}{|c|c|c|c|c|c|}
\hline Peak\# & Ret. Time & Area & Height & Area \% & Height \% \\
\hline 1 & 7.521 & 142312 & 16626 & 11.488 & 12.498 \\
\hline 2 & 7.962 & 1096456 & 116397 & 88.512 & 87.502 \\
\hline Total & & 1238768 & 133022 & 100.000 & 100.000 \\
\hline
\end{tabular}




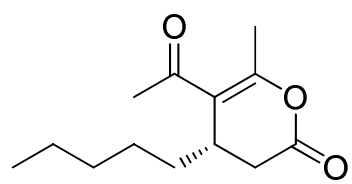

3j

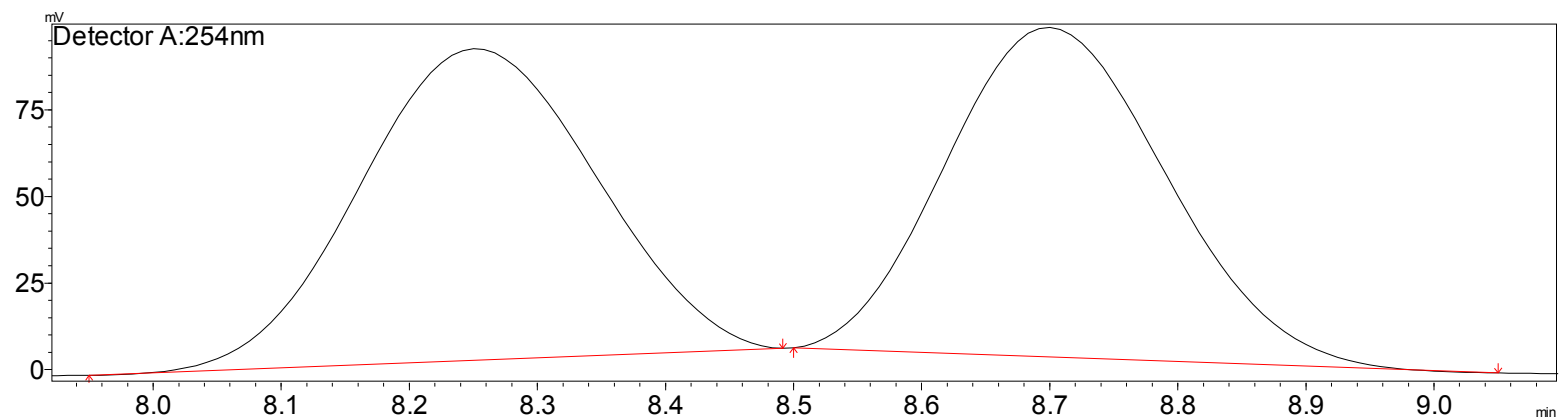

\begin{tabular}{|c|c|c|c|c|c|}
\hline Peak\# & Ret. Time & Area & Height & Area \% & Height \% \\
\hline 1 & 8.248 & 1151783 & 90083 & 50.295 & 48.629 \\
\hline 2 & 8.695 & 1138285 & 95165 & 49.705 & 51.371 \\
\hline Total & & 2290069 & 185248 & 100.000 & 100.000 \\
\hline
\end{tabular}

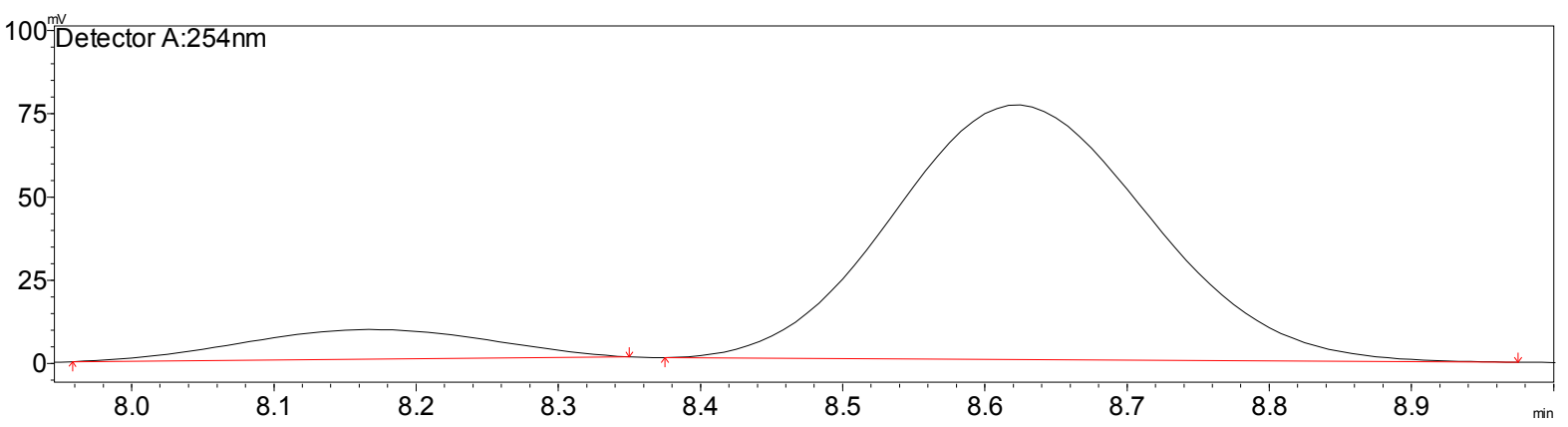

\begin{tabular}{|c|c|c|c|c|c|}
\hline Peak\# & Ret. Time & Area & Height & Area \% & Height \% \\
\hline 1 & 8.165 & 107227 & 8869 & 10.034 & 10.400 \\
\hline 2 & 8.618 & 961428 & 76404 & 89.966 & 89.600 \\
\hline Total & & 1068655 & 85273 & 100.000 & 100.000 \\
\hline
\end{tabular}



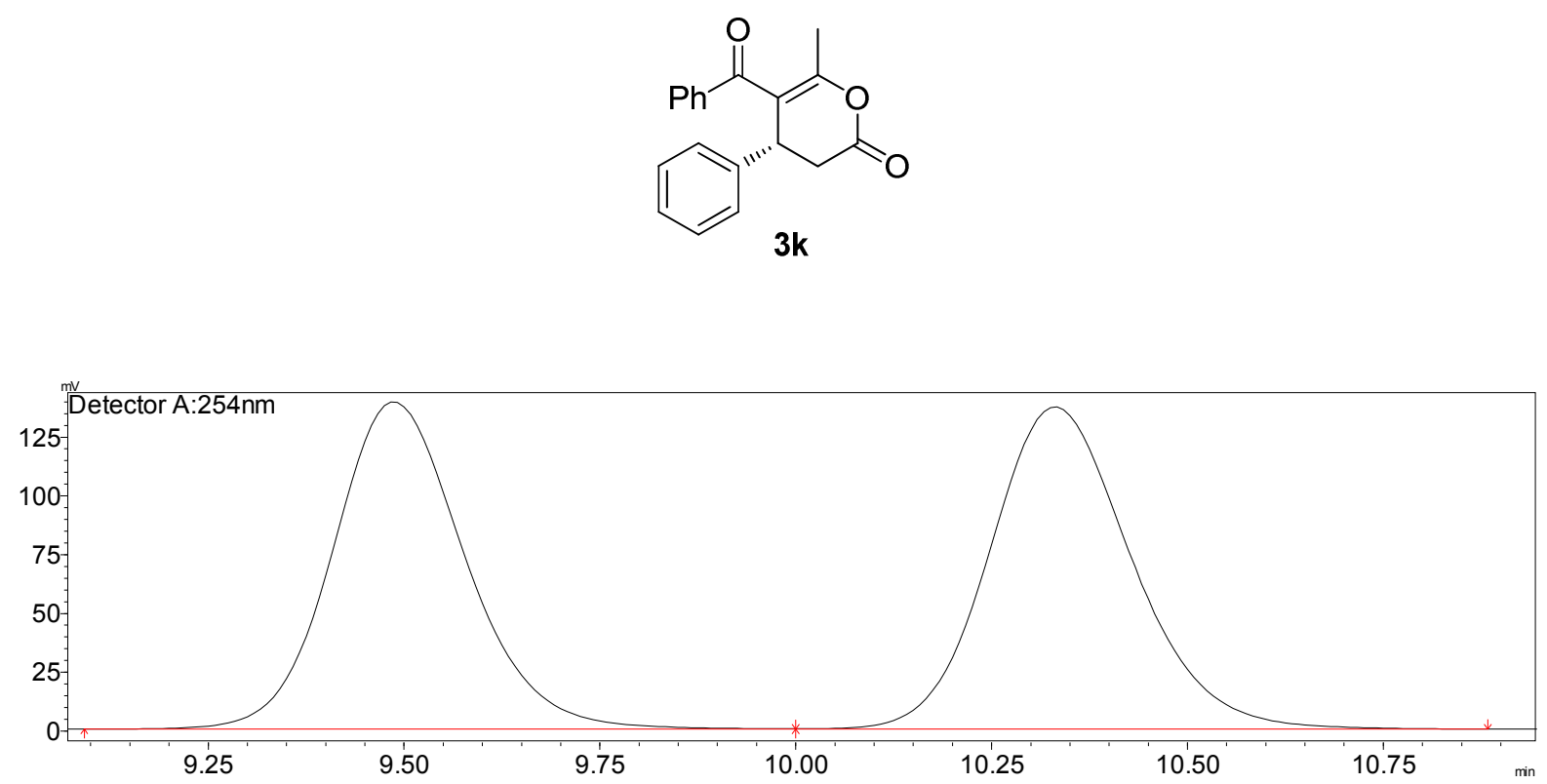

\begin{tabular}{|c|c|c|c|c|c|}
\hline Peak\# & Ret. Time & Area & Height & Area \% & Height \% \\
\hline 1 & 9.483 & 1636545 & 139214 & 48.640 & 50.385 \\
\hline 2 & 10.327 & 1728056 & 137084 & 51.360 & 49.615 \\
\hline Total & & 3364601 & 276298 & 100.000 & 100.000 \\
\hline
\end{tabular}

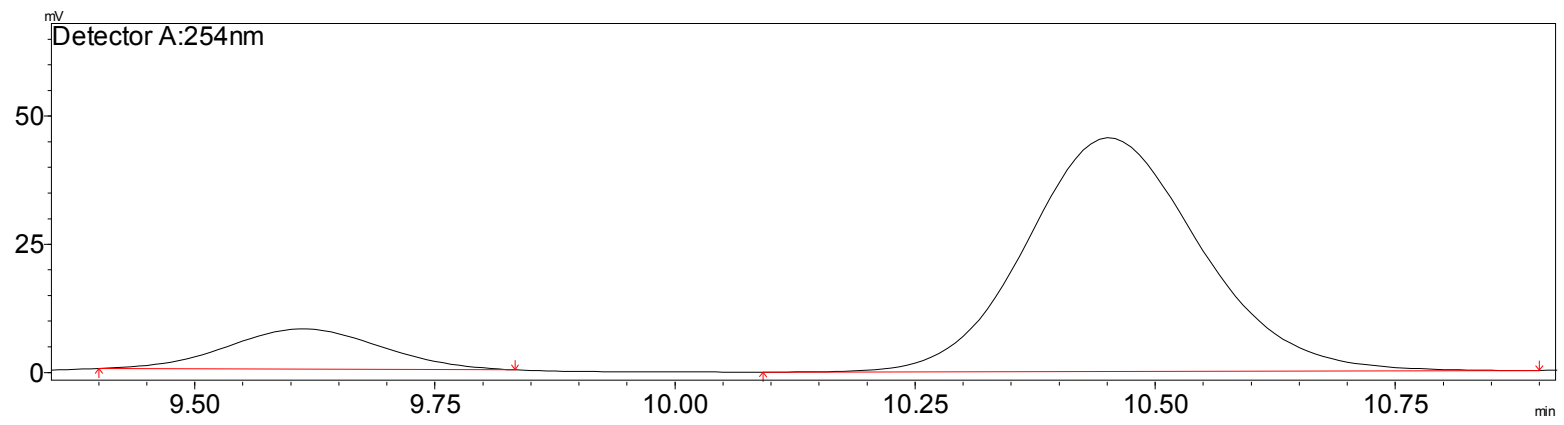

\begin{tabular}{|c|c|c|c|c|c|}
\hline Peak\# & Ret. Time & Area & Height & Area \% & Height \% \\
\hline 1 & 9.608 & 87353 & 7850 & 13.220 & 14.699 \\
\hline 2 & 10.447 & 573412 & 45555 & 86.780 & 85.301 \\
\hline Total & & 660764 & 53405 & 100.000 & 100.000 \\
\hline
\end{tabular}



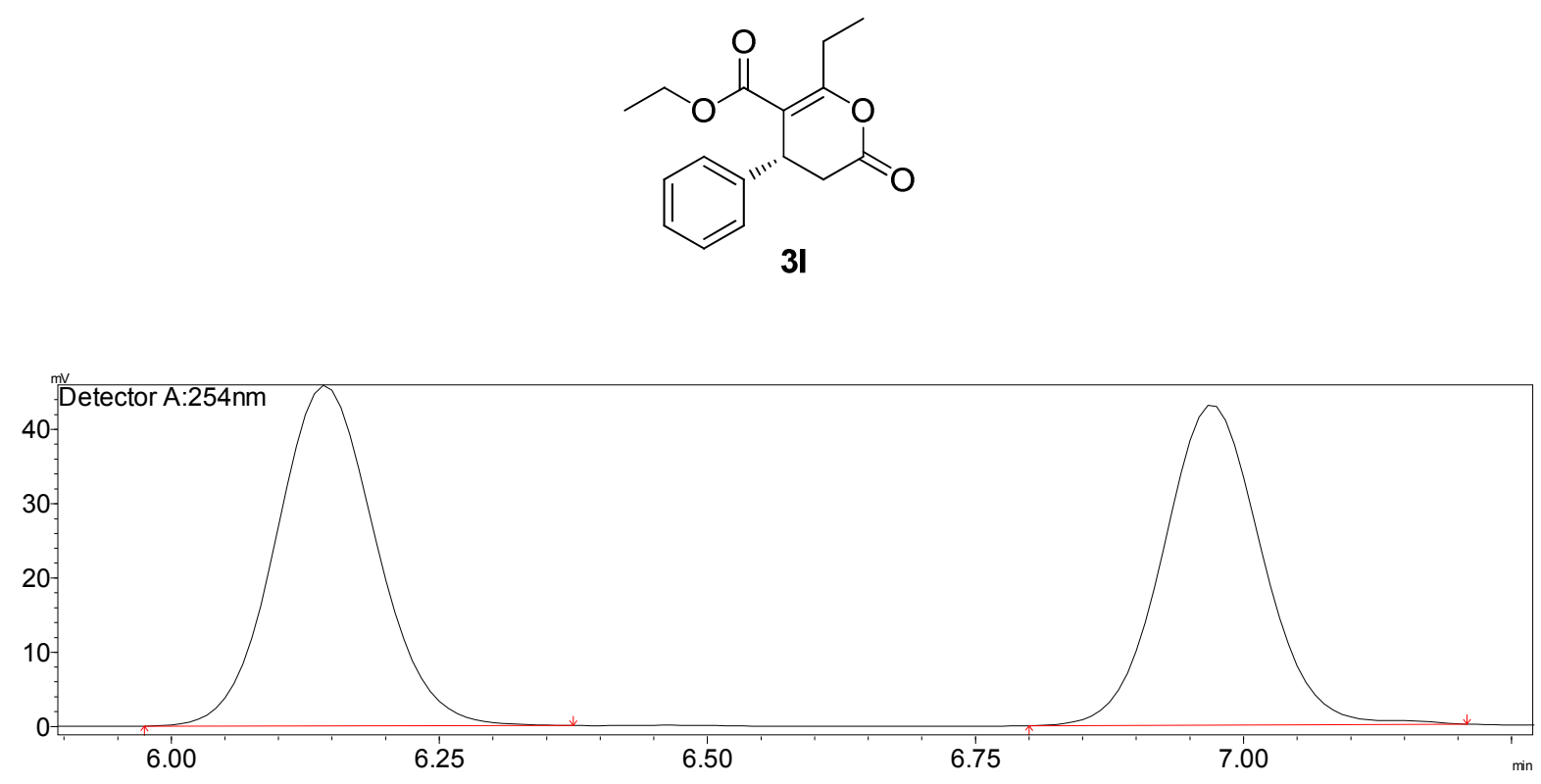

\begin{tabular}{|c|c|c|c|c|c|}
\hline Peak\# & Ret. Time & Area & Height & Area \% & Height \% \\
\hline 1 & 6.139 & 297907 & 45838 & 51.918 & 51.563 \\
\hline 2 & 6.966 & 275899 & 43060 & 48.082 & 48.437 \\
\hline Total & & 573806 & 88898 & 100.000 & 100.000 \\
\hline
\end{tabular}

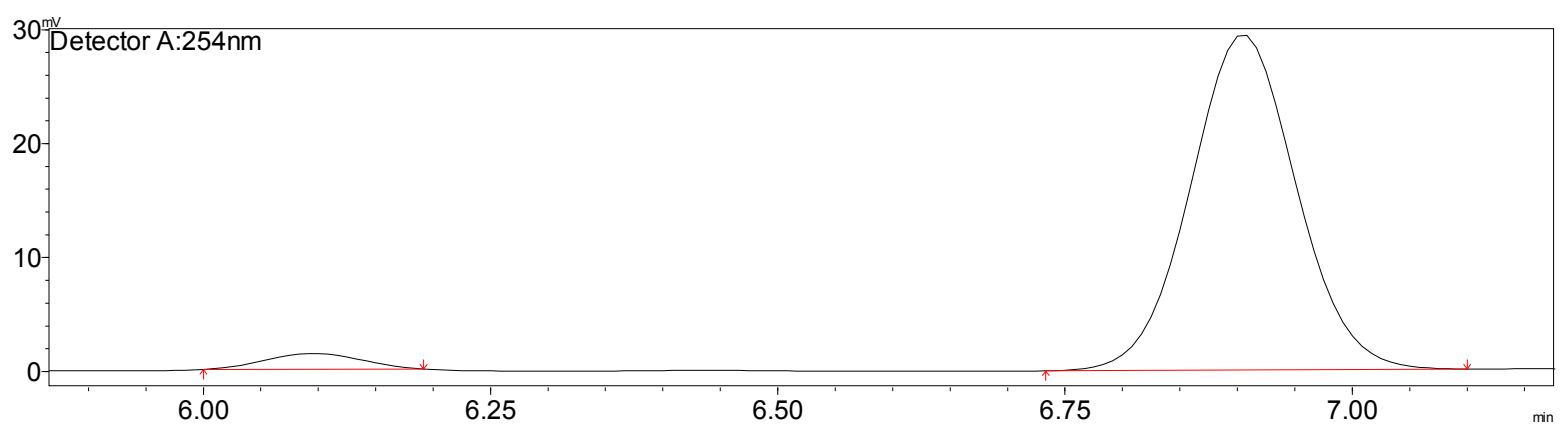

\begin{tabular}{|c|c|c|c|c|c|}
\hline Peak\# & Ret. Time & Area & Height & Area \% & Height \% \\
\hline 1 & 6.091 & 8029 & 1389 & 4.079 & 4.515 \\
\hline 2 & 6.900 & 188812 & 29366 & 95.921 & 95.485 \\
\hline Total & & 196841 & 30755 & 100.000 & 100.000 \\
\hline
\end{tabular}



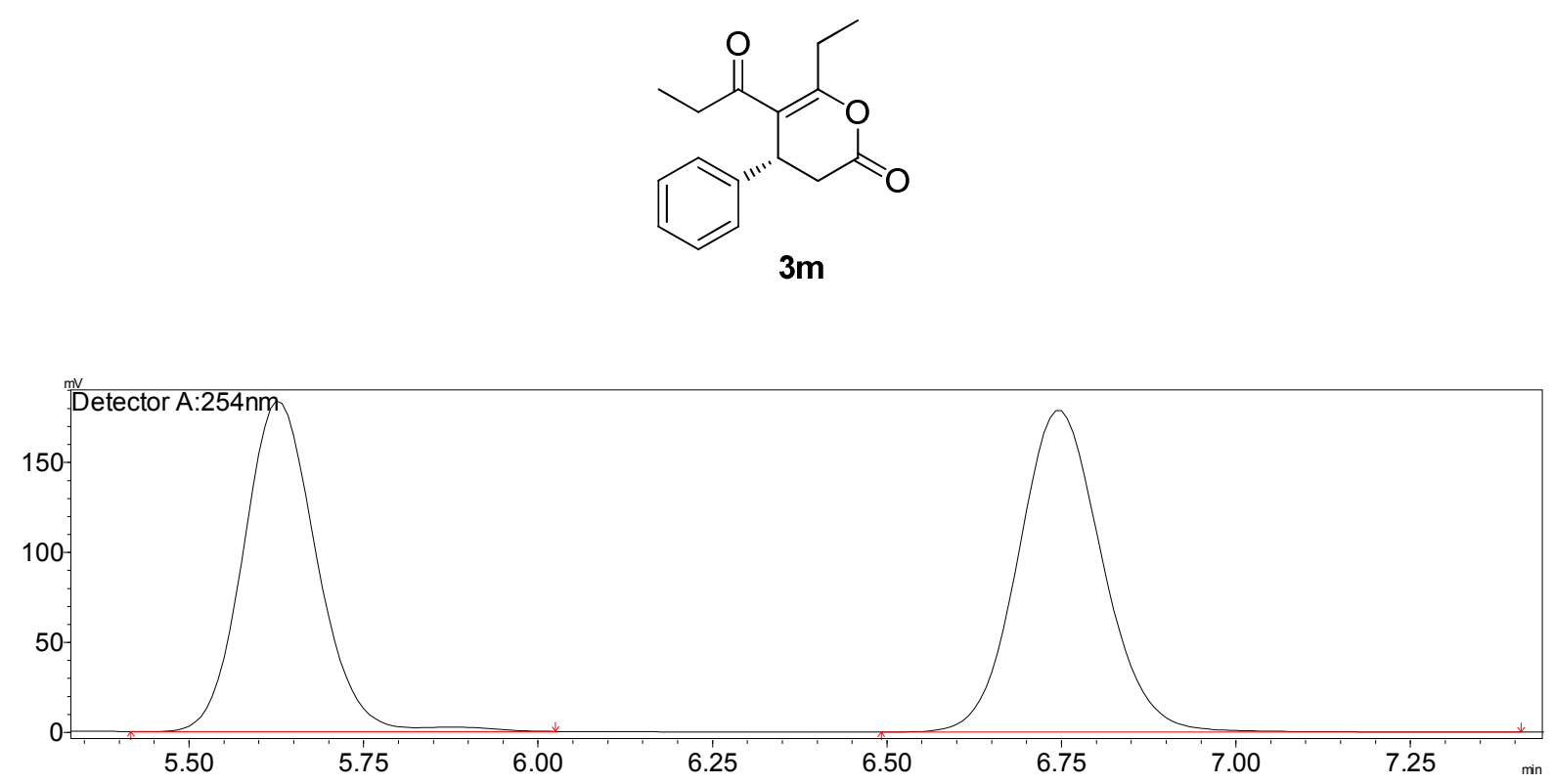

\begin{tabular}{|c|c|c|c|c|c|}
\hline Peak\# & Ret. Time & Area & Height & Area \% & Height \% \\
\hline 1 & 5.623 & 1341289 & 183841 & 47.251 & 50.713 \\
\hline 2 & 6.741 & 1497362 & 178674 & 52.749 & 49.287 \\
\hline Total & & 2838651 & 362515 & 100.000 & 100.000 \\
\hline
\end{tabular}

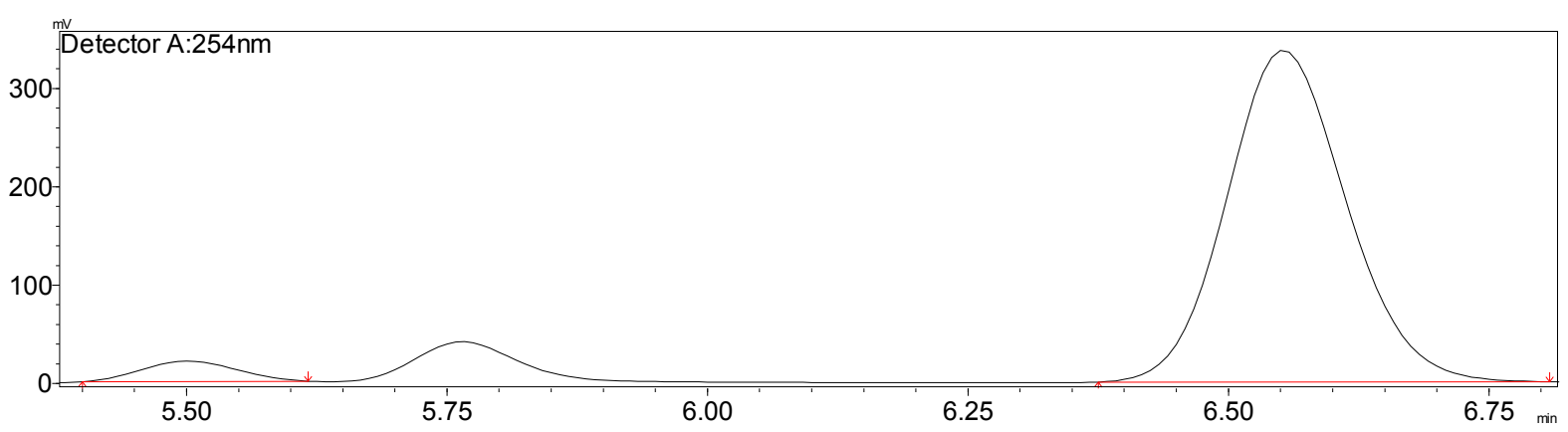

\begin{tabular}{|c|c|c|c|c|c|}
\hline Peak\# & Ret. Time & Area & Height & Area \% & Height \% \\
\hline 1 & 5.497 & 130606 & 20668 & 4.629 & 5.779 \\
\hline 2 & 6.548 & 2690968 & 336975 & 95.371 & 94.221 \\
\hline Total & & 2821574 & 357642 & 100.000 & 100.000 \\
\hline
\end{tabular}



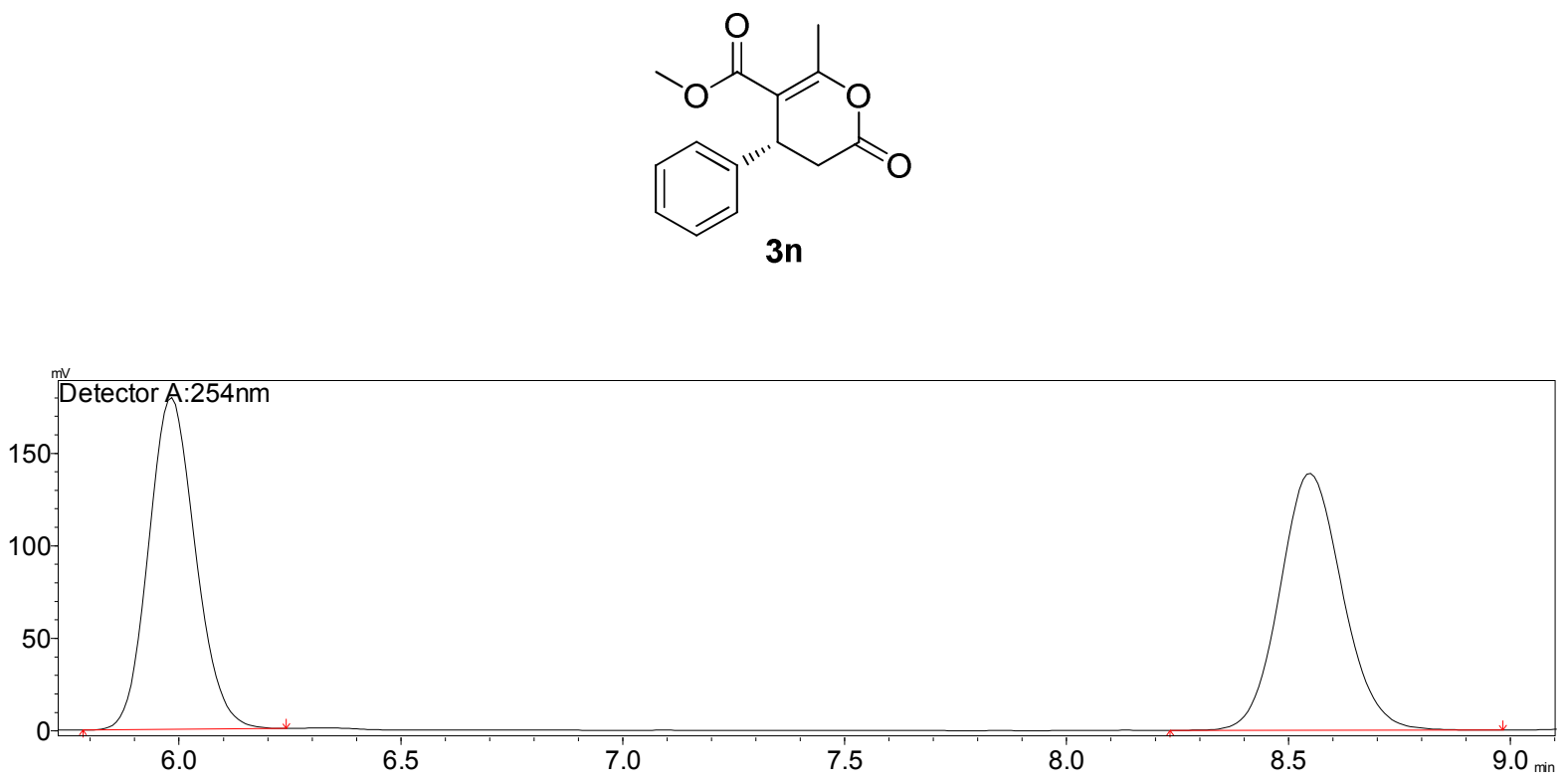

\begin{tabular}{|c|c|c|c|c|c|}
\hline Peak\# & Ret. Time & Area & Height & Area \% & Height \% \\
\hline 1 & 5.977 & 1319105 & 179306 & 49.162 & 56.347 \\
\hline 2 & 8.544 & 1364069 & 138913 & 50.838 & 43.653 \\
\hline Total & & 2683174 & 318219 & 100.000 & 100.000 \\
\hline
\end{tabular}

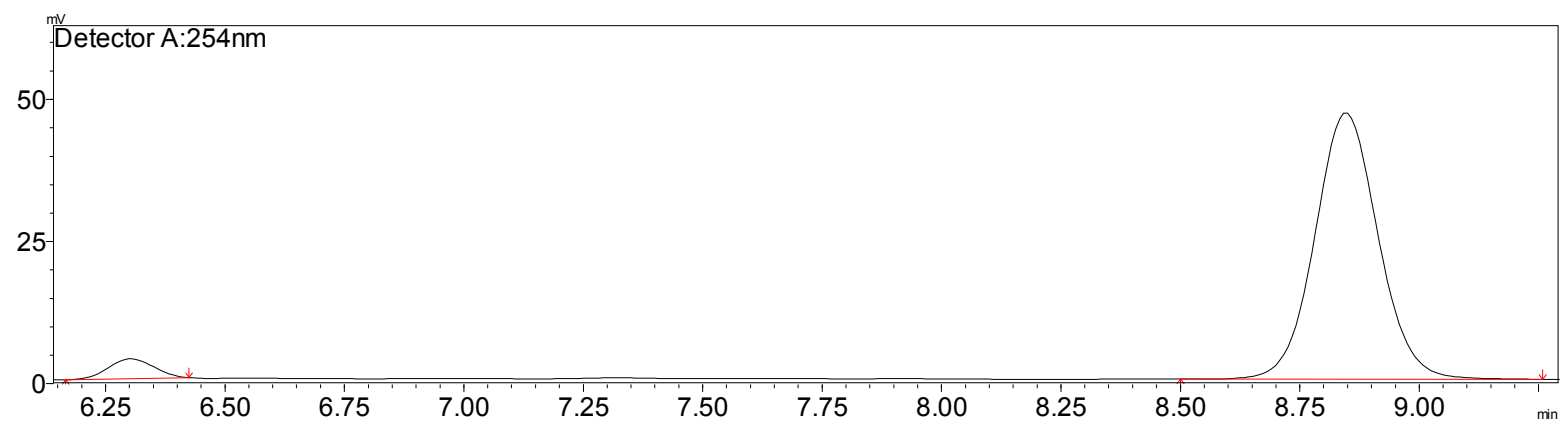

\begin{tabular}{|c|c|c|c|c|c|}
\hline Peak\# & Ret. Time & Area & Height & Area \% & Height \% \\
\hline 1 & 6.299 & 23310 & 3518 & 5.133 & 6.999 \\
\hline 2 & 8.842 & 430833 & 46740 & 94.867 & 93.001 \\
\hline Total & & 454143 & 50258 & 100.000 & 100.000 \\
\hline
\end{tabular}


<smiles>CCOC(=O)C1=C(C)OC(=O)C[C@H]1c1ccccc1</smiles>

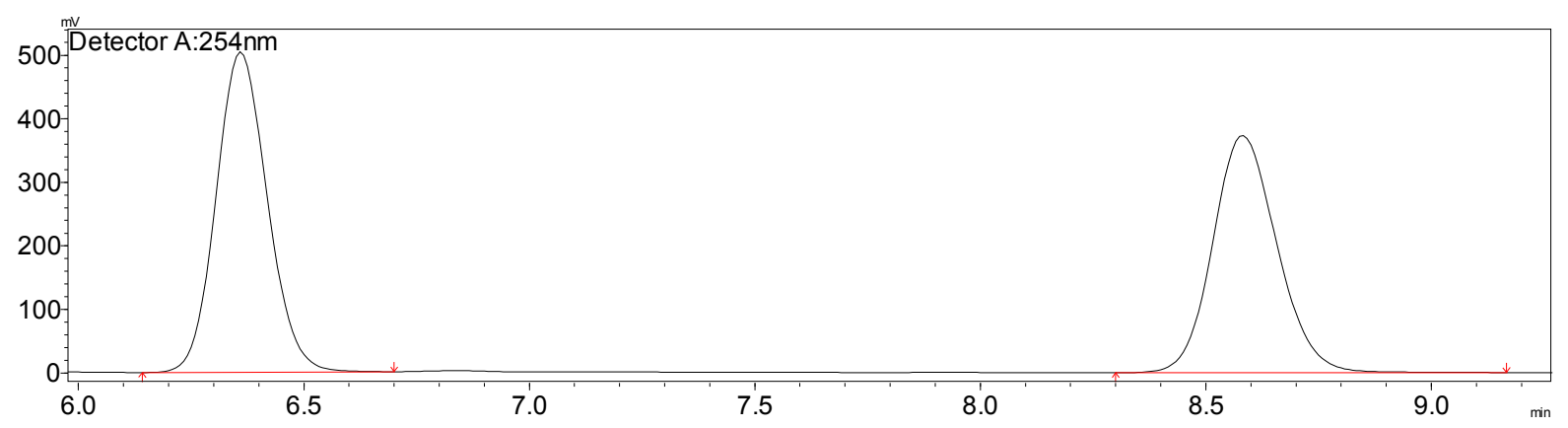

\begin{tabular}{|c|c|c|c|c|c|}
\hline Peak\# & Ret. Time & Area & Height & Area \% & Height \% \\
\hline 1 & 6.355 & 3983407 & 504087 & 51.934 & 57.464 \\
\hline 2 & 8.577 & 3686743 & 373128 & 48.066 & 42.536 \\
\hline Total & & 7670149 & 877215 & 100.000 & 100.000 \\
\hline
\end{tabular}

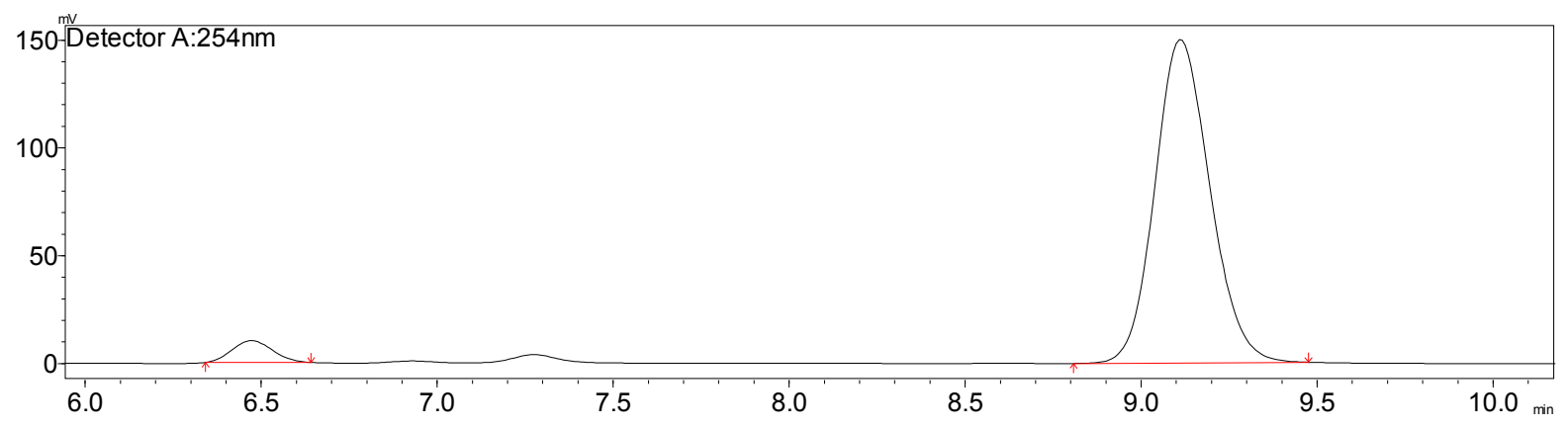

\begin{tabular}{|c|c|c|c|c|c|}
\hline Peak\# & Ret. Time & Area & Height & Area \% & Height \% \\
\hline 1 & 6.468 & 80547 & 10116 & 4.704 & 6.320 \\
\hline 2 & 9.107 & 1631902 & 149958 & 95.296 & 93.680 \\
\hline Total & & 1712449 & 160074 & 100.000 & 100.000 \\
\hline
\end{tabular}



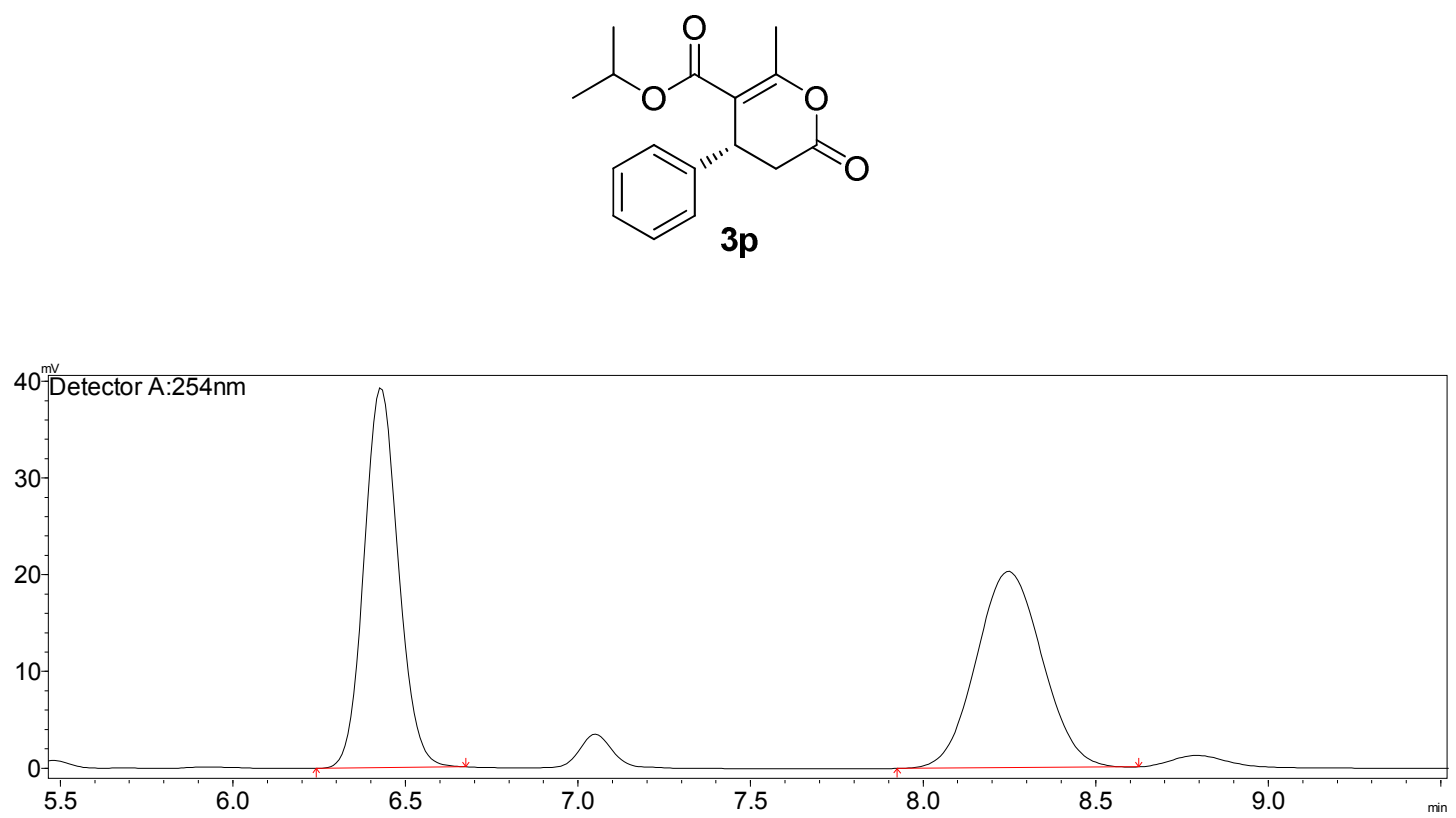

\begin{tabular}{|l|l|l|l|l|l|}
\hline Peak\# & Ret. Time & Area & Height & Area \% & Height \% \\
\hline 1 & 6.424 & 271454 & 39299 & 50.185 & 65.928 \\
\hline 2 & 8.243 & 269449 & 20310 & 49.815 & 34.072 \\
\hline Total & & 540903 & 59609 & 100.000 & 100.000 \\
\hline
\end{tabular}

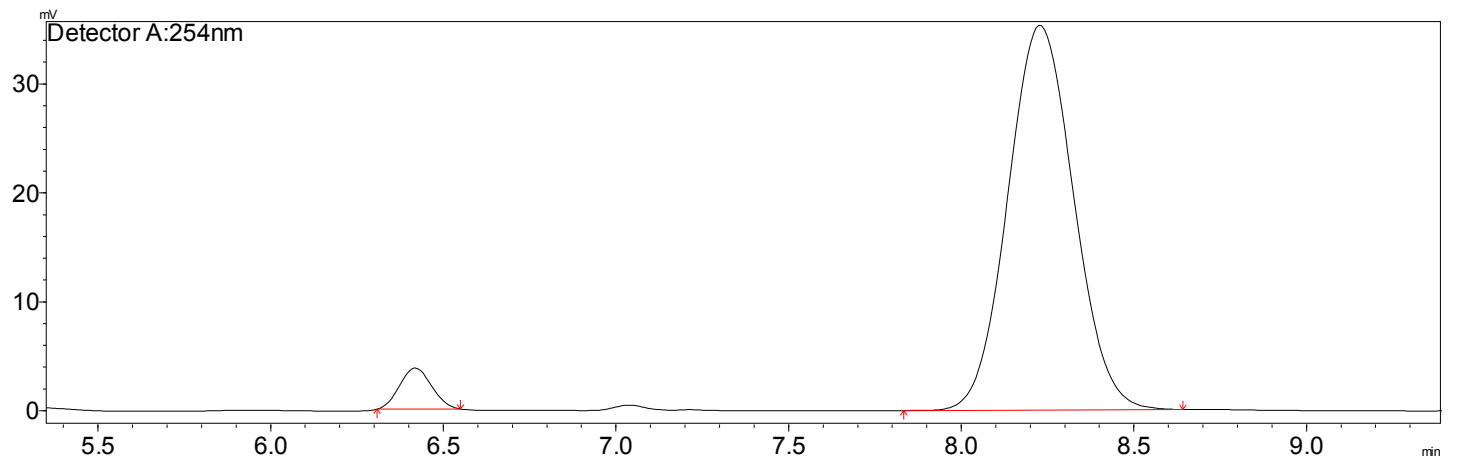

\begin{tabular}{|c|c|c|c|c|c|}
\hline Peak\# & Ret. Time & Area & Height & Area \% & Height \% \\
\hline 1 & 6.414 & 24272 & 3767 & 4.921 & 9.637 \\
\hline 2 & 8.224 & 468969 & 35323 & 95.079 & 90.363 \\
\hline Total & & 493241 & 39091 & 100.000 & 100.000 \\
\hline
\end{tabular}



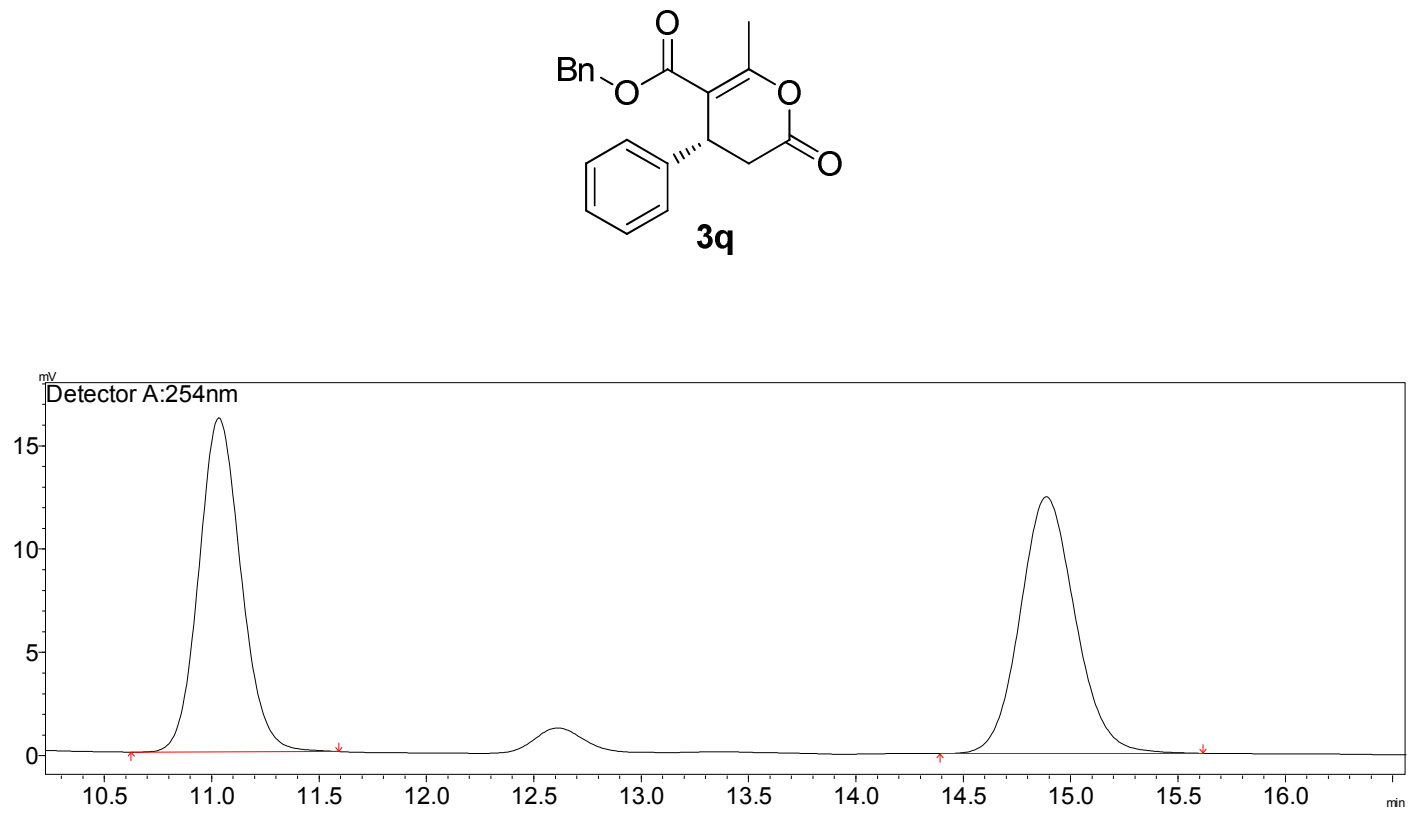

\begin{tabular}{|c|c|c|c|c|c|}
\hline Peak\# & Ret. Time & Area & Height & Area \% & Height \% \\
\hline 1 & 11.030 & 220854 & 16175 & 49.827 & 56.540 \\
\hline 2 & 14.883 & 222387 & 12433 & 50.173 & 43.460 \\
\hline Total & & 443241 & 28609 & 100.000 & 100.000 \\
\hline
\end{tabular}

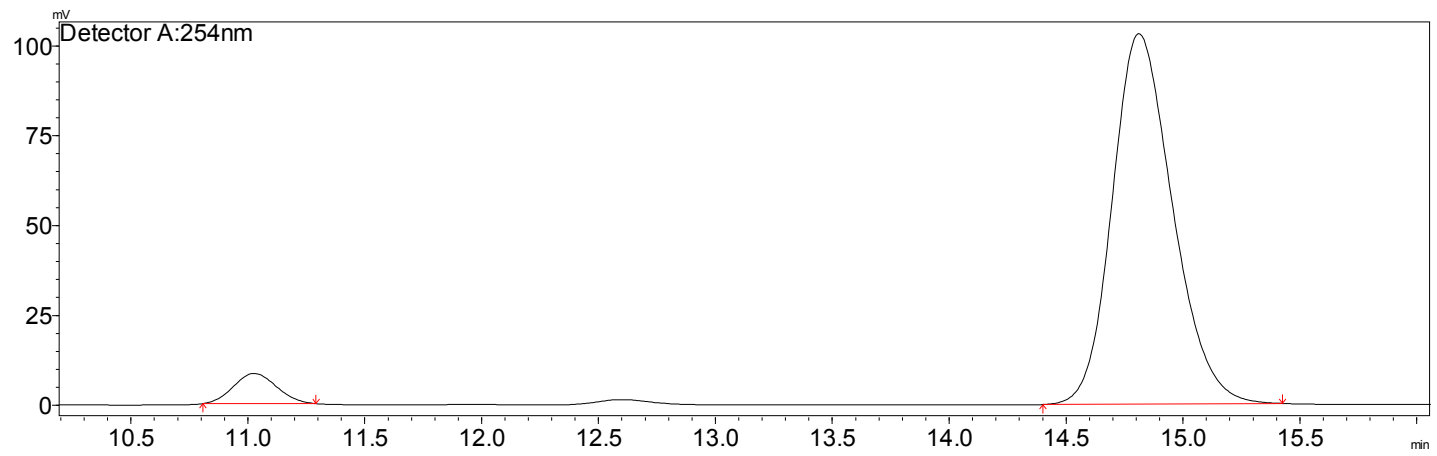

\begin{tabular}{|c|c|c|c|c|c|}
\hline Peak\# & Ret. Time & Area & Height & Area \% & Height \% \\
\hline 1 & 11.023 & 107378 & 8401 & 5.487 & 7.535 \\
\hline 2 & 14.807 & 1849692 & 103091 & 94.513 & 92.465 \\
\hline Total & & 1957070 & 111492 & 100.000 & 100.000 \\
\hline
\end{tabular}

